\title{
Gender, Crime and Punishment: Evidence from Women Police Stations in India*
}

SOFIA AMARAL ${ }^{\dagger}$
SONIA BHALOTRA

April 3, 2019
NISHITH PRAKASH ${ }^{\S}$

\begin{abstract}
We study the impact of an innovative policy intervention in India that led to a rapid expansion in 'all women police stations' across cities in India on reported crime against women and deterrence. Using an identification strategy that exploits the staggered implementation of women police stations across cities and nationally representative data on various measures of crime and deterrence, we find that the opening of police stations increased reported crime against women by 22 percent. This is due to increases in reports of female kidnappings and domestic violence. In contrast, reports of genderspecific mortality, self-reported intimate-partner violence and other non-gender specific crimes remain unchanged. We also show that victims move away from reporting crimes in general stations and that self-reported use of support services increased in affected areas. The implementation of women police stations also led to marginal improvements in measures of police deterrence such as arrest rates.
\end{abstract}

Keywords: Women police station, Crime against women, Women in policing, India, Pro-active behaviour

*We thank Girija Borker, Eleonora Guarnieri, Andreas Kotsdam, Anandi Mani, Maria Micaela Sviatschi, Stephen Ross, Sheetal Sekhri, Helmut Rainer and Espen Villanger for helpful comments and suggestions. We also thank seminar participants at Northeastern Universities Development Consortium (Cornell), North American Econometric Society (Atlanta), European Economic Association Conference (Cologne), American Urban Economics Association Conference (New York), Barcelona Summer Forum, Italian Development Economics Conference (Florence), Center for Studies of African Economies Conference (Oxford), ifo Institute (Munich), Indian Statistical Institute (Delhi), Chr. Michelsen Institute (Bergen), University of Connecticut, University of Essex and International Center for Research on Women (Washington, DC). We are also thankful to Daniel Keniston, the Rajasthan Police, Abhiroop Mukhopadhyay and Lakshmi Iyer for sharing their data. The authors acknowledge excellent research assistance of Zahari Zahiratul. Sofia Amaral acknowledges funding from the Leibniz Association. This work was also supported by the Economic and Social Research Council (ESRC) through the Research Centre on Micro-Social Change (MiSoC) at the University of Essex, grant number ES/L009153/1. We are responsible for all remaining errors.

${ }^{\dagger}$ Corresponding author - ifo Institute and CESifo: amaral.sofiafernando@gmail.com.

${ }^{\ddagger}$ ISER - University of Essex, UK: srbhal@essex.ac.uk

${ }^{\S}$ University of Connecticut, US: nishith.prakash@uconn.edu 


\section{Introduction}

Across the globe, women are under-represented in law enforcement. ${ }^{1}$ While law enforcement is typically considered as a male-dominant occupation, the fact that women have been shown to be less prone to corruption, exhibit more pro-social traits and more gender equal norms raises the question as to whether improved diversity along gender lines is a route to improved effectiveness (Brollo and Troiano, 2016; Eckel and Grossman, 1998; Beaman et al., 2009). Indeed, recent evidence, finds that the incorporation of women into male-dominant professions has also been shown to equalize gender norms and attitudes among males in such professions (Dahl et al., 2018). At the same time, recent concerns over rising levels of violence against women and poor deterrence of this type of crime increases public demand for governments to take steps to address ways of preventing this form of crime (Garcia-Moreno et al., 2006; Telegraph, 2013) ${ }^{23}$. We consider this problem by investigating the implications for women of an innovative form of policing in India - the implementation of all women police stations (WPS).

This paper investigates the causal effects of the placement of WPS in Indian cities on incidence of violence committed against, pro-active behaviours towards violence nd measures of crime deterrence for this type of offense. The recent rise in the rates of violence against women is striking and makes violence against women the fastest growing crime rate in the country - see Figure 1. One explanation for this rise is attributed to an increase in women's willingness to report crimes as a result of improved political representation in local governments and mediatic reporting (Iyer et al., 2012; McDougal et al., 2018). We consider the role of the implementation of WPS as another explanation of this upward trend. This form of policing provides safe spaces for women willing to use formal support services. WPS are also stations that would typically employ female officers purposely trained to handle gender-based violence crimes. The placement of WPS is expected to be effective for two mais reasons. First, by lowering the costs of reporting a crime to the police as WPS allow women to report a crime in an environment that is perceived as having less stigma associated with gender-based crimes, less corrupt and more female-friendly

\footnotetext{
${ }^{1}$ For example, recent data shows that the share of female police officers is $6 \%$ in India, $10 \%$ in the U.S, $17 \%$ in Liberia, $29 \%$ in England and Wales and 33\% in Uganda (Prenzler and Sinclair, 2013; Hargreaves et al., 2016; Secretary-General, 2015).

${ }^{2} \mathrm{~A}$ major example of this is the fact that the Security Council of the United Nations has taken several initiatives aimed at improving female presence in its missions and aimed at doubling the share of female representation by 2020 from of $10 \%$.

${ }^{3}$ In India there is considerable awareness of this problem and one such example is the acknowledgment coming from the Prime Minister Narenda Modi where he stated on the International Women's Day of 2015: "Our heads hang in shame when we hear of instances of crime against women. We must walk shoulder-to-shoulder to end all forms of discrimination or injustice against women" (The Hindu, 2015).
} 
(Miller and Segal, 2014) ${ }^{4}$. Second, there is abundant evidence from political economy that greater in female representation improves the quantity and quality of the provision of public-goods preferred by other women (Chattopadhyay and Duflo, 2004; Clots-Figueras, 2011; Matsa and Miller, 2013; Bhalotra and Clots-Figueras, 2014; Ahern and Dittmar, 2012; Iyer et al., 2012).

WPS is a form of policing that is widely used across the world and that typically involves the creation of police stations that employ only female officers specialized in handling crimes committed against women with a sensitive nature such as domestic violence, rape and other forms of gender-specific offenses (Natarajan, 2016). The first WPS in the world opened in Indian state of Kerala in 1973 and since then its use has been rolled-out to many other cities in India (see Figure 3). As of 2013, India had 479 such stations spread out across most states. We use a newly assembled data set on crimes at the city-level and, data at the state and district-level we investigate how the placement of WPS changes crime rates of offenses committed against women and arrests of these forms of crime. To identify the causal effect of WPS, our identification strategy relies on exploiting the exogenous variation in various forms of the introduction of the policy across cities, states and districts through differences-in-differences models. First, we identify the effects of the placement of WPS across major metropolitan cities in India and find that the opening of station increased reported crimes committed against women in comparison to cities without a WPS. This increase is due to changes in reports of domestic violence and female kidnappings.

Next, to supplement our city-level evidence, we exploit the variation in the implementation of the policy across states and years and find similar results as those of the effects at the city-level. Finally, we look at the effects on arrest rates and find that in states where the policy was first implemented arrest rates of female kidnappings also increased. This result is consistent with the hypothesis that improvements in female police presence improve the deterrence of gender-based crimes ${ }^{5}$.

\footnotetext{
${ }^{4}$ Anecdotal evidence that women prefer to discuss crimes committed against them of a sensitive nature with other women are plenty (new, 2013, 2016; Telegraph, 2013). Qualitative evidence from the U.S. also reveals that officers stereotypes, education and race are major factors determining victim's blame in rape offenses and the handling of cases (Pattavina et al., 2007; Burt, 1980).

${ }^{5}$ Following Becker (1968) a rise in the expected probability of punishment should decrease the supply of crime yet, empirical evidence for this result is mixed, and there is evidence of non-linear effects (Hjalmarsson, 2008; Bindler and Hjalmarsson, 2017). The possible explanations that have been put forward for the lack of results or even counterintuitive results involve for example the increase learning of criminal behaviour due to exposure to other criminals (Bayer et al., 2009). When it comes to domestic violence, there is limited research on the deterrence hypothesis, and the evidence is mixed (Amin et al., 2016; Iyengar, 2009; Aizer and Dal Bó, 2009; Sherman and Harris, 2015). In this paper we interpret the rise in arrest rates as the initial effects through which first there is an initial rise in arrest rates that as time passes leads potential offenders to change their decisions to commit a crime leading to fall in crime.
} 
The main threat to our identification strategy is the presence of time-varying unobservables that correlated with both the placement of WPS and our main outcomes of interest, i.e. measures of violence against women. To deal with this problem in our estimates include state-linear trends in our estimations to account for any state-wide variation in unobservable factors (e.g., implementation of other gender-based policies). Next, we test for the presence of pre-trends and do not find evidence of its existence at the city or state-level. This is consistent with qualitative evidence that shows that the decision to place WPS was part of a complex process that is not correlated with previous crime rates or other gendered policies (Natarajan, 2016).

Second, to understand whether our results are driven by changes in reporting behaviour or incidence of violence against women (e.g., due to a backlash through improving women's representation) we investigate the effects of WPS on crimes whose reporting-bias is expected to be lower (Iyer et al., 2012; Sekhri and Storeygard, 2014). We find that after the placement of WPS female-specific mortality measures, including dowry death rates, did not vary. We also find that individual level measures of self-reported incidence of intimate-partner violence did not change. Next, using detailed police station-level data on reported crimes we find that in urban areas (i.e., where WPS are available), reports of crimes committed against women fell in general stations and this was accompanied by an increase in reports of this form of crime in urban areas where WPS are available. This effect is of 7 times larger in magnitude which suggests that victims are more likely to report in WPS and that effects are not simply due to a potential shift of cases across stations of different types. As a result, we attribute our findings to a change in women's willingness to report crimes rather than a change in incidence of crimes committed against women which would require an effect on measures of female mortality ${ }^{6}$. Finally, to ensure spurious results do not drive our findings (due to, for instance, changes in policing practices) we investigate the effects of the placement of WPS on other non-gender based crimes such as theft of riots and find that these were not affected by the placement of WPS.

To supplement our evidence at the city-level, we show two additional pieces of evidence of the effects of WPS placement by looking at the effects at the state and district-level. The main motivation for this is the fact that the policy was rolled-out outside of the sample of cities we can test and for this reason, we also test if the policy also had similar effects when we consider a wider policy variation definition. First,

\footnotetext{
${ }^{6}$ There is abundant evidence that lethal forms of crime are difficult to go undetected by the police and thus are less likely to be subject to measurement concerns such as changes in incentives to report.
} 
we use the variation at the state and year level in the use of the policy over the period of 1988 and 2013. Consistent with our previous results we find an increase in the rates of violence against women reports in states that implemented the policy without any concomitant effects on other forms of crime. Second, we use the fact that in the state of Jharkhand the use of WPS was rolled-out in its districts in 2006 while in the neighbouring state of Bihar this policy was only in place in 2012. We use this feature and exploit the causal effect of WPS in districts in Jharkhand in comparison to districts in Bihar ${ }^{7}$ Our results are once again consistent with our previous findings.

This paper adds to the growing literature on the economics of violence against women. While recent evidence has focused on the role of income and unemployment in determining violence against women (Aizer, 2010; Anderberg et al., 2016; Bobonis et al., 2013), this paper considers the role of bureaucratic representation in affecting women's use of policing services a feature that is of seldom consideration in the literature. The exceptions are (Kavanaugh et al., 2017; Perova and Reynolds, 2017; Miller and Segal, 2014; Iyer et al., 2012) ${ }^{8}$. Kavanaugh et al. (2017) use geo-coded information on the placement and timing of women's justice centers in Peru and find that after the opening of these centers domestic violence decreased. The authors find that this is due to improvements in women's female empowerment. Also, the authors also investigate the effects on children's educational outcomes and find large gains in human capital accumulation. Our paper differs from that of Kavanaugh et al. (2017) is two ways. First, WPS in India do not have a role beyond that of law and order, and for this reason, its effects on other outcomes that go beyond reporting and police effectiveness are less likely to exist. Next, our focus is on female empowerment through participation with the police (as we look at measures of reporting and deterrence) a feature previously not considered yet crucial in empowering women and deterring crime (Comino et al., 2016). Instead, Kavanaugh et al. (2017) focus on measures of the self-reported incidence of intimate-partner violence.

Our paper is also related to Miller and Segal (2014) who investigate the effects of incorporating women in the police in the U.S. on reporting rates of domestic violence. The authors use victimization and police-reported information to understand the effects of affirmative action policies in between 1970

\footnotetext{
${ }^{7}$ Jharkhand is a new state created by carving districts from the state Bihar in 2001. The use of this natural experiment has also been used to look at economic growth and political incumbency advantage (Asher and Novosad, 2015; Iyer and Reddy, 2013).

${ }^{8}$ Wagner et al. (2017) and Blair et al. (2016) use experimental data to look at the differential effects of gender and ethnicity in policing. Wagner et al. (2017) find that female officers are no different than their male counterparts regarding malpractice. Blair et al. (2016) tests the effect of the ethnic composition of policing teams in police effectiveness towards minorities.
} 
and 1990s that significantly raised the share of female officers from 3.4 to $10 \%$. The authors find that this increase led to a rise in reporting rates of domestic violence incidents by 4.5 percentage points and a decrease in female homicides committed by the intimate-partner. These results are consistent with a change in reporting behaviour and an improvement in policing quality. This paper, like in ours and that of Kavanaugh et al. (2017) and unlike that of Perova and Reynolds (2017), disentangles the reporting effect from other unobservable changes that could have occurred (such as other improvements in policing) and also finds that the effects of improvements in female representation in the police are concentrated in crimes committed against women.

This paper is also related to Iyer et al. (2012) who find that improvements in female representation at the local level, increased reporting of crimes committed against women. This effect is driven by improvements in female empowerment and exposure to women in leadership positions. In our paper, we find that WPS improve the willingness to report a crime but also its deterrence (through changes in arrest rates). Thus, our finding is likely to be driven by changes in reporting behaviour but also in policing quality (as in Miller and Segal (2014)).

This paper is related to two broad streams of literature. First, to the literature considering the causes of crimes committed against women (Gulesci, 2017; Card and Dahl, 2011; Amaral and Bhalotra, 2017; Tur-Prats, 2015; Iyer et al., 2012; Aizer, 2010; Borker, 2017) and in particular we add to this stream of literature by looking into the role of deterrence policies in effect this form of crime (Iyengar, 2009; Aizer and Dal Bó, 2009; Amaral et al., 2015). Second, we add to the literature on female representation and targeting of public spending and decisions that are more aligned with women's preferences (Chattopadhyay and Duflo, 2004; Glynn and Sen, 2015) and general effectiveness due to better representation (Adams and Ferreira, 2009). It contributes by looking at the role of gender-balanced police composition in promoting safety for other women, a feature that has received little attention in development despite crime reporting being considered a measure of trust and institutional development (Soares, 2004; Banerjee et al., 2012).

This paper is organized as follows. In section 2 we provide a detailed description of female representation in the police in India and the functioning of WPS. In section 3 we describe the data and in section 4 the different identification strategies. In section 5 we present results and section 6 concludes. 


\section{Background}

\subsection{Incorporation of Women in the Police}

In India women, have been part of law enforcement since 1939 and this incorporation was not initiated as a result of a specific policy. In fact, over the years, women were inducted to the police due to the need to address the increase in female offenders and the rise in crime committed against women (Natarajan, 2016). Despite the early introduction of women in the police, the percentage of females in the Indian police force still averages less than 5\% between 2005 and 2013 (see Table 20). Within the country, the presence of women in policing also varies substantially: from $8.4 \%$ in Tamil Nadu and 5\% in Maharashtra to $1.6 \%$ in Uttar Pradesh and $0.4 \%$ in Assam. Nonetheless, the share of female officers has risen sharply since 1990, a trend common to that in other countries (Miller and Segal, 2014) and that also follows a general rise in police strength (Figure 2).

Regarding the distribution of female officers across ranks of the police, the share of women is higher among the bottom and top rank positions. ${ }^{9}$ Over the period 2005-2013, the share of women in these rankings has also increased but in a non-uniform way. For instance, the share of Constables rose at a faster rate ${ }^{10}$. This is relevant given that it highlights the fact that the introduction of female officers is not leading to a sorting into positions with lower exposure to civilians. What's more, this is consistent with the opening of WPS leading to an increasing the need for female Constables.

Finally, the timing at which women first entered the police force varies considerably across states. In Kerala and Maharashtra women first entered the police in 1939. Delhi and Gujarat followed in 1948 and, the last states incorporating women officers were Uttar Pradesh and Tamil Nadu in 1967 and 1973, respectively. However, for most states, the implementation of WPS did not follow directly from this initial incorporation of women. For instance, Kerala (the first state to open a WPS) did so 34 years since the initial incorporation of women in the police. Tamil Nadu (the state with the highest numbers of WPS about 40\%), had a 19-year gap between incorporating women and implementing WPS in 1992. This is

\footnotetext{
${ }^{9}$ Ranking of police positions in India is as follows: Director of Intelligence Bureau, Commissions of Police or Director General of Police, Joint Commissioner of Police, Additional Commissioner of Police, Deputy Commissioner of Police, Superintendent of Police, Additional Superintendent, Inspectors, Sub-Inspectors and Assistants to the Inspectors, Head Constables and Constables. Throughout the paper, we consider the six highest ranks to be a single category, followed by a separate category of inspectors, a category of head constables, and the remaining of constables.

${ }^{10}$ The information regarding police force by rank and gender is only available from 2005
} 
important as it suggests that (i) women were not incorporated in the police to serve only in WPS, and (ii) the different forms of feminization of policing seem to be unrelated across states and within states. We show in Figure 4 that indeed there is no correlation between women's incorporation in the police and the policy roll-out.

\subsection{The functioning of women police stations in India}

The use of specialized cells to deal with crimes of a sensitive nature such as committed against women has been recommended since the National Police Commission of 1977 (Natarajan, 2016). These WPS are stations that typically (or tentatively) employ only female officers and, only handle cases related to violence committed against women. For this reason, officers placed at WPS receive specialized training in dealing with victims and in processing these types of crimes. The purpose of these stations is to create a male-free environment where women can report and be cooperative in the investigation. To our knowledge, these stations do not have independent authority so that filing of cases and arrests should be approved by the Head Constable of a general station.

The first WPS opened in Kerala in 1973. Since then, this form of policing spread across the country and in 2013 almost all states had at least one WPS (see Figure 3). The growth in WPS between 2005 and 2013 has been large and happened in all but two states: Maharashtra and Himachal Pradesh (Table 15). Tamil Nadu is the state with the highest density of stations, and these are well spread out across the state (Figure 3). These stations are generally seen as a successful initiative by State Home Departments and for this reason there is a staggering increase in WPS across the country (Department, 2012). This paper presents the first comprehensive evaluation of the effects of WPS on crime and deterrence measures.

\subsection{WPS and the reporting and recording of cases in India}

In order to better understand the effects of WPS, we provide a brief description of the process through which an offense would typically be dealt with. Once a crime occurs a victim can decide whether to proceed to a station and report a case or not (reporting effect). Once in a station, the attending officer must decide whether fill-in a First Investigative Report and proceed with a formal investigation or not (recording effect). Finally, after an investigation, officers may or may not make an arrest (effectiveness 
effect). The implementation of WPS would make available to victim's a more female-friendly environment that is specialized in dealing with cases of violence against women. Thus, we expect that following the roll-out of a WPS reports of VAW crimes increase. Second, because in WPS officers are less likely to exhibit skewed gender norms about the roles of women or tolerance of violence committed against them, we expect that the recording and subsequent filling of FIR's to increase. Finally, if female officers increase the effort in investigating these types of crimes and/or the actual form of policing makes crime investigation more simple than we would expect a rise in the effectiveness in handling of these crimes.

In our data we only fully observe some of the stages. First, in the first phase, crime reporting is a latent variable that one could only measure through victimization data. Nonetheless, since we do observe crimes with different levels of reporting incentives (e.g. domestic violence versus female mortality) we attempt to address the first effect by looking at different forms of crime. Next, we use information at the state-level on charge-sheet rates and arrest rates to investigate the effects on the two remaining variables. This process follows closely Iyer et al. (2012) where we use the author's data and extend it to 2013.

\section{Data}

Women police stations: The information on the dates of opening of WPS in cities and of the roll-out of the policy was gathered from multiple sources. The main source is the yearly reports on Policing Organization from the Bureau of Police Research and Development (BPRD). These reports contain the city location of stations across India and its year of roll-out since 2005. We use this information to provide a detailed description of the path of WPS implementation over the period of 2005 and 2013. We combine this information with crime records data from the major metropolitan areas in India. This information was collected from the National Crime Records Bureau (NCRB). It is worth noticing that, while there are many more cities with WPS we are restricted to the cities contained in the NCRB publications.${ }^{11}$ This data is used in the city-level analysis.

For the state-level analysis, we gathered information about the timing of adoption of WPS across states from the BPRD reports and (Natarajan, 2016). Since most states, implemented WPS before

\footnotetext{
${ }^{11}$ Information at the city-level from India is known for being difficult to gather (Greenstone and Hanna, 2014) and we are not aware of any other publicly available source of information on crimes we could use. To the best of our knowledge, this is the one of the most comprehensive city-level panel data sets assimilated and analysed for India to date.
} 
2005 we complement the remaining data by contacting each state Ministry of Home Affairs and Police Headquarters separately ${ }^{12}$. The variation in WPS policy are presented in Table 14.

Crime: We make use the National Crime Records Bureau (NCRB) yearly data. The NCRB provides data from police-reported crimes for cognizable crimes prescribed under the Indian Penal Code. This is the major source of administrative data on law and order in India. The data is based on information gathered from two processes. First, once an incident occurs and is reported, the police are required to register a First Information Report (FIR) - see Iyer et al. (2012) for an overview. Second, this information is aggregated by each police station and then reported to the NCRB that then aggregates it at different levels. We use this information from 2005 to 2013 for the city-level analysis and from 1988 to 2013 for the state-level analysis.

The NCRB provides data for 18 categories of crime which we use to construct three major crime categories. These are violence against women, non-gender based violence, and property. ${ }^{13}$ The release of each crime category varies over time with rape being consistently reported over the years, female kidnappings started being reported as a separate category since 1988, and the remaining categories in 1995. These differences do not affect our estimations since we always include year dummies, but they condition the categories we are able to track over time since 1988. Figure 1 shows the trend in the three major crime categories since 1995. Over the period, reports of violence against women have risen and at a faster rate than the remaining categories.

The crime data in city-level analysis makes use of the statistics from the metropolitan areas database. Also, to increase the sample of cities, we also combine this information with the statistics available from the crime area-level database. Overall, our sample consists of an unbalanced sample of 76-89 cities. The list of cities by year is provided in Table 19 is in Appendix. The data from our state-level analysis is from the state-level statistics and is available since 1988 i.e. the year at which we have at least two categories of crime we can track.

In cities, over the period, the rate of crimes committed against women per 100,000 population was

\footnotetext{
${ }^{12}$ We also cross-checked our information with media dissemination information on the opening of WPS's (or Mahila Thana's in Hindi)

${ }^{13}$ VAW includes domestic violence, rape, molestation, sexual harassment, kidnapping of women and girls. Non-gender based violence includes murder, riots, kidnapping of males, dacoity, arson and hurt. Property crime includes theft, robbery and burglary. A detailed description of these categories can be found in the Indian Penal Code.
} 
of 534. This rate is considerably higher in cities with a WPS (626) when compared to those that do not have a WPS (188). Within the category of violence against women, the rate of domestic violence is the highest with 330 reports per 100,000 population. In spite of its fastest growth, the rate of property and non-gender based violence is higher. On average, there are 2187 reports of property crimes per 100,000 population and 2137 of non-gender based violence. These rates are also higher across cities with and without a WPS (Table 20).

To explore mechanisms, we also collect crime-specific arrests and charge-sheeting rates from the NCRB reports. This data is only available at the state-level. Moreover, we also collect information on genderspecific mortality available at the state-level cause (i.e. accidental deaths, dowry deaths, suicides or murder due to love affairs).

Demographic, political and law and order data: We gather relevant demographics including total population, gender and caste composition and literacy to be used as control variables. These data is collected from the urban agglomeration and state-level Census data of 1991, 2001 and 2011. We interpolated the data for the remaining intervening years. We also gather information on police strength by gender and rank from the annual reports of the NCRB and BPRD. We also include a dummy for state election years gathered from the Election Commission.

\section{Identification Strategy}

To investigate the effects of increased presence of women in the police through the implementation of WPS, we make use of a difference-in-differences identification strategy applied to the distinct levels of aggregation of the data (as explained before these are city and state. This is done for two main reasons. First, because while WPS are mostly implemented in cities in many states the policy was expanded to other urban and rural areas that we cannot identify in the sample of the crime data at the city-level. Thus, to be precise about the effects of the policy we extend our main analysis to a state-level analysis. The second reason is data driven. While the WPS policy started in 1973, we are only able to match crime and city-level since 2005. To take advantage of the information we gathered on the year in which states started implementing WPS we also show results that make use of information since 1988 up to 2013. 
First, we will exploit the staggered implementation of WPS in Indian cities. Second, by investigating the roll-out of the policy across districts and states. We describe each of the identification issues and empirical strategy below.

\section{City-Level Analysis}

Using city-year data and the precise information on the year of the introduction of women-only stations, we estimate the change in reported crime rates across before and after the placement of WPS in comparison to cities that did not open WPS. The estimating equation is as follows:

$$
\text { Crime }_{c s t}=\alpha_{0}+\delta_{1} \text { Post WPS } S_{c t}+\beta X_{c t}+\beta X_{s t}+\gamma_{c}+\lambda_{t}+\phi_{c} t+\epsilon_{c s t}
$$

where Crime $_{c s t}$ is the crime rate per 100,000 population (in logarithms) in city $c$ of state $s$ measured in year $t$. The variable Post $W P S_{c s t}$ is a dummy that takes the value one in the years following the opening of a WPS in given city $c$. In our specification, we include a vector of city-level controls $\left(X_{c s t}\right)$ that include the ratio of males to females to take into account for the demographic gender inequalities that have been shown to have a positive effect on gender-specific crimes (Amaral and Bhalotra, 2017). We also include literacy rate to take into account for the underlying differences in the willingness to commit crime and reporting behaviour (Erten and Keskin, 2016). Finally, at the city-level, we also take into account for the differences in management of policing by including a dummy as to whether the city has a Police Commissioner system. We also take into account for differences in cities across states by including as controls factors that could impact upon crime differently (e.g. the share of female officers). In addition to this, we also include a rich set of fixed-effects. We include city fixed effects, $\gamma_{c}$ to control for permanent unobserved determinants of gender-based violence across cities (Tur-Prats, 2015; Alesina et al., 2016); year fixed effects to non-parametrically adjust for national trends in crime and, city-linear trends $\left(\phi_{c} t\right)$ to adjust omitted time-varying factors in cities across. The coefficient of interest is $\delta_{1}$ measures the differential effect of implementing a WPS within $c$ in a year $t$ in comparison to other cities in that same year. All standard errors are clustered at the city-level and regressions to account for possible correlated shocks to city-level crimes over time. All regressions are weighted by population size. The term $\epsilon_{c s t}$ is the idiosyncratic error term.

State-Level Analysis We use the timing and state variation in the initiation of the roll-out of WPS in 
states as a natural experiment to identify the effects on gender-specific crime. We follow a difference-indifferences strategy similar to (1) but where we exploit the variation in the policy roll-out:

$$
\text { Crime }_{s t}=\alpha_{0}+\delta_{2} \text { PostW PSPolicy }_{s t}+\beta X_{s t}+\gamma_{s}+\lambda_{t}+\phi_{s} t+\epsilon_{s t}
$$

where Crime $_{s t}$ is the crime rate in a state-year. PostW PSPolicy $s$ is a dummy variable that takes values one in the years including and following a state initiation of the roll- out WPS in the state. In our specifications, we always include state and year fixed-effects $\left(\gamma_{s}\right.$ and $\left.\lambda_{t}\right)$ as well as state-linear trends $\left(\phi_{s} t\right)$. Also, we include a rich set of controls $\left(X_{s t}\right)$ that include sex ratio, literacy rate, state income per capita, police per capita, election year dummies, the share of scheduled castes and scheduled tribes and. We also show results where we take into account the roll-out of the introduction of political gender quotas in local governments and the introduction of the National Rural Employment Guarantee Scheme (NREGA) (Iyer et al., 2012; Amaral et al., 2015). The coefficient of interest is $\delta_{2}$ which captures for the differential effect of the policy across treated and control states. The policy variation used is large for instance, over the period of 1998-2013 there are total of three control states, two treatment states (i.e. those that implemented the policy before 1988) and eleven states that implemented the policy at different points in time over the period in our sample ${ }^{14}$. Standard-errors are clustered at the state-level.

In both (1) and (2) we are able to address the plausible sources of endogeneity through the introduction of a rich set of controls, fixed-effects and area-specific linear trends. As a result, we take our model to accurately capture the causal effect of the implementation and roll-out of WPS. To further inspect that our results are not biased due to omitted trends we first provide test for the presence of pre-existing trends. Next, we inspect whether the implementation of WPS have an effect on crimes that are not expected to change with this policing form. The failure to reject that WPS lead to changes in non-gender specific crimes would be suggestive of the presence of omitted factors that are common to all forms of crime. Finally, the remaining possibility is the presence of omitted trends that are specific to gendered crimes. To inspect for this we look at the effects on other forms of crime that are gender-specific but are

\footnotetext{
${ }^{14}$ The states included in the sample are Andhra Pradesh, Bihar, Gujarat, Haryana, Himachal Pradesh, Punjab, Madhya Pradesh, Rajasthan, Uttar Pradesh, Karnataka, Kerala, Tamil Nadu, West Bengal. The newly created states of Telangana, Jharkhand, Chhattisgarh and Uttaranchal are merged with their pre-2001 state boundary definitions. Since Jharkhand initiated the policy prior to the state of Bihar in this case we take the year of 2006 as the year in which the policy had an effect for the state of Bihar under the pre-2001 boundaries definition.
} 
not expected to vary with a change in the incentives to report crimes.

\section{Results}

\section{Determinants of Placement of Women Stations and Parallel Trends}

Since our main identification strategy relies on a difference-in-differences experiment, we start by presenting some evidence on its exogeneity. First, we start by showing that there is no apparent correlation between the year's states incorporated women in the police and the use of the WPS policy - see Figure ??. Next, we estimate the determinants of the placement of stations in cities and, of the determinants of the roll-out of the policy in states, respectively show in Tables 1 and 2 . In both, we regress the potential determinants of a dummy variable that takes values one if in a given city-year or state-year there is a WPS. In Table 1, in column (1) we only include a set of socio-demographic factors, and we do not find that there is a correlation between these factors that include sex ratio and literacy rate, and the placement of cities. Next, we include, separately, the share of female officers in the state, whether the city has a Police Commissioner system and, the lag of the crime rate of violence committed against women. These results are reassuring that the placement is not correlated with factors and instead is the results of a complex decision process.

When considering the determinants of the policy across states (in Table 2) we find consistent results when considering socio-demographic correlates. However, we find that the probability of states implementing WPS is decreasing with income per capita; increasing among the states that are most effective in implementing the NREGA and, decreasing in the in states where the local gender political quotas where first implemented. Together these do not show a clear understanding of the underlining causes of states implementing WPS. On the one hand, richer states are less likely to use this form of policing, but at the same time, the implementation of NREGA could have raised the need to improve the response to increasing in crimes committed against women because of the programme as shown in Amaral et al. (2015). On the other hand, it could be that there is some level of competition between gendered policies so that in states where female representation in politics has implemented the roll-out of WPS was neglected. To take these factors into account, we include these controls separately in the regressions. 
For our estimates in (1) and (2) to be valid the required identifying assumption is that treated units (those implementing WPS) and control units must have parallel trends in the main outcome of interest total rate of crimes committed against women. Our estimates of $\delta_{1}$ and $\delta_{2}$ will be biased if control units do not resemble treated units. In Figures 5 and 6 we provide event-study estimates of the effects of WPS in the city and state samples, respectively. It is apparent from these that areas implementing WPS were no different in the pre-period as the coefficients for years before the policy are insignificant. Also, we can see that there is a clear positive effect of the policy that is immediate and remains positive in the years following the placement of WPS.

To the best of our knowledge from discussions with senior officers in the police and at Ministry of Home Affairs (Government of India) - the decision to implement a WPS is part of a complex decision process that involves locations expressing an interest in this form of policing with interest in the same direction from high-ranking police officials and state ministers. Thus, our results are consistent with the fact that plausible determinants of WPS placement do not seem to predict its placement at a given time. Taken this, we now turn to our difference-in-difference estimations results.

\subsection{Effects on Crime}

City-Level Analysis: We present the results from estimating (1) in Table 3. In Panel A we present results where the primary dependent variable is the total rate of reported crimes committed against women and in Panel B total rate of non-gender based violence. Moving from columns 1 to 6 we enrich the specification by first including a set of baseline controls in addition to city and year fixed-effects; next, by including state-linear trends in column 3; controlling for Police Commissioner system in column 4; controlling for the state share of female officers in column 5 and, finally in column 6 , our preferred specification where we include city-linear trends.

Across specifications, we find a positive statistically significant effect on total crimes committed against women with coefficient ranging from 0.5 in the specification without controls to 0.2 in the most parsimonious estimation. Regarding effect sizes, in treated cities, the increase in the rates of violence committed against women was of $21.4 \%$. In column 5 , it is reassuring to see that the inclusion of the total share of female officers does not affect the direction and magnitude of the results. The result suggests that the 
effect of WPS is in the form of policing rather than the share of female officers.

Looking at the effects of opening a WPS on non-gender based violent crimes (Panel B) the effects are not statistically significantly different from zero and importantly, these coefficients are nearer to 0 as we improve the specification (column 3-5). These results suggest that opening WPS led to an increase in gender-specific crimes and was not due to other unobservable changes that could affect all forms of crime. Also, since these effects are concentrated on gender-specific crimes, this placebo results confirm our hypothesis that WPS led to a change in women's willingness to report and not necessarily the existence of male backlash that could have also led to a rise in general crimes. We also test for the effect of WPS in additional crime types (of violence and property crime types) Table 17 in Appendix. Across all 8 different crime rates, we do not find that opening of a WPS change these crimes. This is consistent with previous results in Table 3 and also reassures that WPS did not change other crime types that should not be affected by an increase in incentives for women to report crimes committed against them. This ensures that our results are not driven by a spurious correlation or omitted factors that could affect all crime types equally within the same city-year.

Next, we look at the effects by crime type by disaggregating the rate of total violence against women into its singular component categories to understand which type of crime was more affected. We present these results in Table 5. The variables of interest are the rates of female kidnappings, domestic violence, dowry deaths, molestation, sexual harassment and rape. We find that the effects of WPS are due to increases in the rates of female kidnappings and domestic violence with increases of the magnitude of $22.2 \%$ and $21.7 \%$, respectively. This finding seems to suggest that reporting incentives are likely to matter more among crimes with a medium range of severity and not all forms of crime against women.

Finally, we repeat the test of pre-trend presented in Figures 5 in Table 5. For our main variable of interest, total rate of violence committed against women, we do find evidence of pre-trends in the year preceeding the policy or two years before.

State-Level Analysis: We present the results for the state-level analysis - specification (2) in Table 6 . In Panel A the main dependent variable in the total rate of violence committed against women; in Panel $\mathrm{B}$ the rate of female kidnappings and Panel C Rape rate ${ }^{15}$. Moving from column 1 to 2 we include the set

\footnotetext{
${ }^{15}$ Due to differences in the way crime data was released over time in India we can only track these 2 single categories over the period of $1988-2013$
} 
of socio-economic controls in addition to state and year fixed-effects. In column 3 we also include police force per capita and a dummy for election years in the states. In column 4, we add state-linear trends. In column 5, we control for the local gender political quotas reform following Iyer et al. (2012). In column 6 we control for the differential effect of the NREGA reform and column 7 we also control for the share of female officers in the police in each state-year.

We find that states that started implementing WPS, the total rate of crimes committed against women increased by $22.5 \%$. This increase in partially due to a rise in the rate of female kidnappings which increased by $10.85 \%$. As per before, we do not find a statistically meaningful change in the rate of rapes. As suggested before the reform could have had a larger impact in crimes with lower cost of reporting in comparison to others whose emotional and physical costs is potentially higher as is the case of rapes.

As per before, we reiterate this analysis on crimes which are not likely to change as a result of WPS. We present these in Table 21 in Appendix. We consider as dependent variables the rate of male kidnappings, dacoity, robbery, burglary, thefts and total male deaths. We do not find evidence that in states implementing WPS non-gender specific crimes changes. This placebo test ensures the validity of our estimations.

As a robustness exercise, in columns 8-10 we repeat the main regressions by excluding the state of Tamil Nadu. This state is unlike any other state in the sense that it implemented the WPS policy in an unprecedented form 3. This state has $41 \%$ of all WPS in the country and these are evenly distributed within the state. To understand whether our results are driven by the intensity of the treatment in Tamil Nadu we estimate (2) without it. Our results are not sensitive to the exclusion of this state which shows the importance of the effectiveness of WPS beyond the intensity of the placement.

Finally, we also present a test of the effect of the reform in the years preceding the roll-out of the policy (see Table 7). As suggested in Figures 6 we do not find evidence of differential pre-trends in year before the initiation of the policy, 2 years or 3 years. In Appendix we also present the estimation of (2) with all coefficients. Results are consistent with those find by others - see Table 18.

Additional Evidence from the split of Bihar and Jharkhand: To make use of the full extent of the crime data and to further supplement the validity of our results we exploit the effects of the roll-out 
of WPS using an additional natural experiment. In 2001, three states were created from districts of three largest states. The state of Jharkhand was one of these newly created states that was split from districts of the state of Bihar. This experiment is of interest to this paper as Jharkhand, unlike its former state of Bihar, opened WPS in each of its districts in the year 2006. Thus, we make use of the fact that districts in Jharkhand are likely to be similar in terms of unobservable factors since these were previously under the same state and exploit this feature by comparing the change in crime rates in districts of Jharkhand in comparison to districts in the state of Bihar. The identifying assumption is that districts in Jharkhand would have had the same trend in crime as its counterpart districts in the state of Bihar had it not been for the placement of WPS in the newly created state.

We make use of the district-level data from the NCRB from the years 2001-2011. This implies that in our sample there are 5 pre-treatment years and 6 post-treatment periods and 22 districts in Jharkhand in comparison to 37 in Bihar. In our analysis, we also include similar control variable as those in (2). These are collected from district-level Census for the years 2001 and 2011. In Table 24 we present summary statistics. In Figures ?? we present the means in the total rate of crimes committed against women in the pre and post period. The rightest panel shows the difference in means. As it is clear there is a rise in these rates in districts in Jharkhand. In Table 12 we present differences-in-difference estimation results of the following equation:

$$
\text { Crime }_{d s t}=\alpha_{0}+\delta_{3} \text { Jharkhand }_{d s} \times \text { Post }_{t}+\alpha_{1} \text { Post }_{d t}+\beta X_{d t}+\gamma_{d}+\lambda_{t}+\phi_{s} t+\epsilon_{d s t}
$$

where $_{\text {Crime }}^{d s t}$ is the crime rate in a district, state, year. The variable Jharkhand $d_{d s}$ takes values one if a district is in the state of Jharkhand and Post $t_{t}$ is a dummy variable that takes value one after the year 2006. Thus, $\delta_{3}$ is the difference-in-difference coefficient capturing the differential effect of the WPS across treated (districts in Jharkhand) and control states (districts in Bihar) before-after the placement of $\mathrm{WPS}^{16}$. The coefficient $\alpha_{1}$ captures for the post-2006 general effect on crime in the control districts i.e. those in the state of Bihar that did not receive a WPS. The vector $X_{d t}$ is a vector of socio-economic controls that include sex ratios, literacy rates and share of scheduled castes and tribes. We also include

\footnotetext{
${ }^{16}$ We provide results using the sample of bordering districts to Jharkhand and Bihar and also separately, for all district in both states. In this case, the variable Jharkhand $d_{s}$ takes values one if a district is in the state of Jharkhand and borders Bihar or zero if it is a district in Bihar that broders Jharkhand.
} 
district fixed-effects $\left(\gamma_{d}\right)$ and year dummies $\left(\lambda_{t}\right)$. We also include a set of state linear trends to account for differences specific to each state over time $\left(\phi_{s} t\right)$. All standard-errors are clustered at the district-level. The term $\epsilon_{d s t}$ is the error term.

Table 12 presents the results for rate of total crimes committed against women and the individual categories of rape, female kidnappings, domestic violence, sexual harassment, molestation and dowry deaths. Panel A considers only the sample of neighbouring districts, i.e. those that would be most similar regarding time-varying unobservables. Panel B considers the full sample of districts in each state. We find that the placement of WPS led to an increase in reports of total crimes committed against women, female kidnappings and domestic violence. The coefficients in Panel A are marginally insignificant but we consider this is due to the small sample size $(\mathrm{N}=198)$ as the coefficients in Panel A is similar in magnitude but statistically significant. We find a positive and statistically significant effect on the rate of total violence against women, female kidnappings and domestic violence. The failure to include state linear trends (columns 2) affects our estimates in the sense that its omission leads to an underestimate of the effects of WPS. Regarding effect sizes, the placement of WPS led to an increase in the rate of total crimes committed against women by $30 \%$ - a magnitude consistent with our findings in the city sample. Moreover, WPS led to an increase in the rate of reports of female kidnappings by $41 \%$ and of domestic violence by $87 \%$.

\section{Channels of Transmission}

\subsection{Do WPS lead to a change in the incidence or reporting behaviour of VAW?}

Effects on female mortality rate: In Table 8 we look at the effects on female mortality outcomes. We construct a measure of female mortality that is the sum of police cases by state-year of murders due to love affairs; female suicides; and accidental deaths. Since homicides committed by the intimate-partner is the leading cause of female homicides and given the fact that there is a low probability that deaths go unaccounted for, we use this measure to capture for the incidence of VAW rather than changes in reporting behaviour of women. We find that WPS did not change female mortality. This is consistent with WPS having affected crimes that are more likely to change with reporting incentives rather than 
instigating a change in incidence of VAW that would also affect female mortality rates.

Effects on measures of self-reported intimate-partner violence: We also exploit the variation in state-level exposure to the policy across residents in urban and rural areas using individual-level data from the Demographic and Health Surveys of 2005-2006 and 2015-16. The use of this information is informative due to two main aspects. First, we can consider a measure of self-reported intimate-partner violence, a measure that is typically considered to be subject to less measurement error ${ }^{17}$. Second, within the space of the ten years of the survey rounds, five states have adopted the WPS policy; and the remaining three states have not implemented the policy. This coupled with the fact that the WPS policy is present in urban areas and not rural areas allow us to identify the effect of the policy using a triple difference-in-difference estimation strategy whereby we use as identifying factors (i) treatment and control states; (i) the timing of the policy roll-out and, (iii) whether the respondent resides in urban or rural areas. We present this variation in Table 26. Using this we then proceed to estimate the following triple difference-in-difference model:

$$
I P V_{i s y}=\alpha_{0}+\delta_{1} \text { Treatment }_{s} \times \text { Post }_{y} \times \text { Urban }_{i}+\beta_{1} \text { Treatment }_{s}+\beta_{2} \text { Post }_{y}+\beta X_{i}+\gamma_{s}+\lambda_{y}+\epsilon_{\text {isy }}
$$

where $I P V_{i s y}$ the is the self-reported measure of intimate-partner violence (IPV). The coefficient of interest is $\delta_{1}$ that captures for the differential effect of the roll-out of the WPS policy in treatment states Treatment $_{s}$, before-after its implementation Post $y$ which we measured using the year of implementation of the survey and the roll-out of the survey. Finally, since the policy was only implemented in urban areas, we also exploit the additional source of variation coming from residents in urban versus rural $\left(\operatorname{Urban}_{i}\right)$. To account for unobserved confounders, we also include a vector of woman-specific characteristics that include age, caste and religion dummies, household size, and separately female years of education, number of children born. We present these findings in Table 25. Across specifications, we do not find evidence that women's exposure to domestic violence changed and this result does not differ across forms of IPV (emotional, physical or sexual) or the inclusion of state-urban area dummies that would account for additional unobserved factors that could affect women in urban versus rural areas within the same state.

\footnotetext{
${ }^{17}$ This measure is more likely to be a better candidate to measuring incidence of intimate-partner violence (i.e. domestic violence) because it has less reporting costs (e.g. going to a police station). Yet, social desirability bias and stigma are also factors that may affect the measurement of this variable and for this reason we also present results using female mortality measures.
} 
Put together these results suggest that the implementation of WPS led to a change in measures of VAW that are sensitive to reporting incentives rather than a change in incidence of violence that would likely affect female mortality rates or self-reported intimate-partner violence.

\subsection{Testing the effect on women's willingness to report in WPS}

Evidence from police station-level data: To further show that the results found for measures of VAW that are sensitive to changes in reporting incentives rather than incidence we exploit how reports of VAW to the police changed across stations, i.e. women-only police stations and general stations. We use the data collected by (Banerjee et al., 2012). This data contains information on 73,207 police reports collected from 152 police stations, across ten districts of Rajasthan in the years of 2006 and 2007. We coded VAW crimes following the definitions of the Indian Penal Code. ${ }^{18}$. We then estimate a cross-sectional difference-in-difference model whereby we compare how reports of VAW within treatment districts in Rajasthan (i.e. 4 treatment districts) vary in comparison to reports in stations in control districts (i.e. 6 control districts). We estimate the following:

$$
\text { Crime }_{s d t}=\alpha_{0}+\delta_{1} \text { Treatment }_{d} \times \text { Urban }_{s} \times W P S_{s}+\delta_{2} \text { Treatment }_{d} \times \text { Urban }_{s}+\gamma_{d}+\lambda_{t}+\epsilon_{s d t}
$$

where Crime $_{s d t}$ is the total number of reports to station $s$ in district $d$ during month $t$. The coefficient of interest is $\delta_{1}$ that captures for the differential effect in police reports of VAW across districts implementing the WPS policy $\left(\right.$ Treatment $\left._{d}\right)$, in urban and rural stations $\left(\right.$ Urban $\left._{s}\right)$ and across WPS and non-WPS stations. The coefficient $\delta_{2}$ represents the effect on general stations. We always include district and month-year fixed effects and weight the regressions by district population as measured in the Census 2011. In separate estimations, we also include a monthly station trend and separately district*monthyear fixed effects that would absorb any district unobserved effects at the month-level. Standard-errors are clustered at the station-level.

Due to the richness of the data we are also able to test for the effects of WPS on two separate aspects. First, we validate if changes in women's willingness to report in WPS raises the total reports of VAW

\footnotetext{
${ }^{18}$ Defined as crimes coded as cases that fell under the category of cruelty towards wife (domestic violence); rape; molestation; the Dowry and Woman Act; and cases coded as 493, 494, 495, 496, 497, 498, 509 all defined as crimes committed against women under the Indian Penal Code. This totalized 6,124 reports (approximately 9.3\% of all crimes which is comparable to NCRB statistics.
} 
crimes (as we have otherwise shown before). This is identify through coefficient $\delta_{1}$. Second, we test if women move away from reporting in general stations to reporting in WPS. This would imply that $\delta_{1}$ is positive (i.e. the increase in reports effect) and that $\delta_{2}$ is negative. Importantly, if the magnitude of $\delta_{1}$ is larger than $\delta_{2}$ this would mean that not only WPS lead to a direct shift of cases from general to WPS's but indeed evidence of additional reports being reported in WPS that would have not been reported in general stations in the absence of the policy.

We present these results in Table 9. Consistent with our hypothesis we find a significant and positive coefficient for $\delta_{1}$ and negative coefficient for $\delta_{2}$ for the crime categories of total VAW and domestic violence. It is also worth noticing that coefficients are largely unchanged with the inclusion of state trends (columns 2) and district-year dummies (3). The magnitude of the coefficient is of about 8.35 additional reports in WPS's, and a decrease of 1.35 reports in general stations. This represents an additional 7 reports in WPS.

Finally, we also implement an additional test where we look only at the effect in general stations, across treatment and controls districts across urban areas vis-a-vis the rural station's counterparts. These results are shown in Table ??. We show that the coefficient of the effect of general stations in urban areas is very similar to coefficient $\delta_{2}$ shown in Table 9. Second, the coefficients for rural areas are not statistically different between treatment and control districts. This falsification exercise allows showing evidence that there are no potential unobserved confounders between districts implementing WPS and those that did not.

Evidence from self-report measures of use of support services: A theory of change of VAW involves the development of pro-active behaviours that eventually lead to a decrease in VAW. A change in women's willingness to report VAW crimes as a result of the WPS would, therefore, be consistent with women being more likely to seek for support in their social networks (i.e. friends) or along formal services. To test for this, we follow the same identification as in model (4) and use as dependent variable a measure of self-report use of formal or informal support services. This module is asked to a small sample of women who respond to have been victims of intimate-partner violence and asks respondents about whether they have mentioned the problem to family members (including the partner and former partner); police; a neighbour; social organisation; lawyer; religious leader or a doctor. We run regressions of the form of (4) and test if women affected by the WPS were more likely to use support services. We construct an index 
of usage of support services that range from 0 (no use) to 7 (use of all modes of support services) and also a dummy variable if the respondent used at least one form of service. We present these results in Table 10. We find that usage of support services increased which is consistent with the WPS leading to an overall change in pro-active behaviours that is correlated with increases in reports to the police.

\subsection{Effects on measures of deterrence}

In Table 11 we consider the effects of WPS on police effectiveness. We hypothesise that WPS rise the overall quality of police in handling gender-based crimes as the creation of WPS facilitated a more femalefriendly space for victims to cooperate with the police and also, the availability of police staff specifically trained to handle these types of offences. We find that after the implementation of WPS in states ${ }^{19}$ arrest rates due to female kidnappings increased by $15 \%$. This is consistent with our finding from Table 6 that after a rise in reports of female kidnappings, policing treatment of these type of offence also increased. This result is important given the fact that improving women's access to justice is not a sufficient condition to deter crimes committed against women. Deterrence of this type of offence, much like other crimes, is required for total incidence to decrease.

As a robustness exercise, we exclude the state of Tamil Nadu. This state is unlike any other state in the sense that it implemented the WPS policy in an unprecedented form 3. This state controls $41 \%$ of all WPS in the country, and these are evenly distributed within the state. In order to understand whether our results are driven by the intensity of the treatment in Tamil Nadu we estimate (2) without this state. Our results are not sensitive to the exclusion of this state which shows the importance of the effectiveness of WPS beyond the intensity of the placement.

These results are also consistent with evidence from the U.S. showing that increases in the presence of female officers led to increases in the rate of reporting of cases of domestic violence which led to a subsequent decline in incidence Miller and Segal (2014). In addition, these finding are also in line with those of Amin et al. (2016) who show, using cross-country data that, improvements in protective domestic violence legislation would have saved about 33 million women between 1990 and 2012.

\footnotetext{
${ }^{19}$ Information on arrests and charge-sheet is only available at the state-level.
} 


\section{Conclusion}

Violence against women and girls (VAWG) poses a major obstacle to achieving inclusive prosperity and ending poverty. This type of violence is arguably hindering social and economic development and its repercussions for long-term development are large. Across the globe, estimates show that nearly 1 billion women will experience intimate partner violence or non-partner sexual violence in their lifetime. Moreover, homicides committed by partners remain one of the highest causes of female mortality Garcia-Moreno et al. (2006); Amin et al. (2016) .

This paper investigates how improvements in female representation in policing impacts upon the rates of crimes committed against women and its subsequent arrests. Our findings show that the implementation of women police stations in India led to significant increases in the rate of crimes reported to the police in the order of magnitude of $22 \%$ rise. This in turn led to a rise in arrests of crimes whose reports increased.

The policy we investigate is one of low intensity and in a context of women-only police stations with limited resources. Yet, in spite of this we find results that improvements in access to justice can rise women's willingnes to approach law and order services. This feature is core in economic development

models but there was limited evidence for this when it comes to addressing violence against women Soares (2004). This paper addresses this issue for a sample cities and states in India.

Our paper makes a contribution to the literature on crime and violence against women by showing how improvements in women's access to justice and quality of police service provision can impact upon deterrence of crimes committed against women-one of the most under-reported forms of crime. Across the globe women are under-represented in law enforcement, this shows that the inclusion of women in this traditionally male occupation can improve women's access to justice and help deter future crime. 


\section{References}

, 2013. More female police officers are needed to end violence against women in afghanistan.

, 2016. Why aren't u.s. police departments recruiting more women?

Adams, R. B., Ferreira, D., 2009. Women in the boardroom and their impact on governance and performance. Journal of financial economics 94 (2), 291-309.

Ahern, K. R., Dittmar, A. K., 2012. The changing of the boards: The impact on firm valuation of mandated female board representation. The Quarterly Journal of Economics 127 (1), 137-197.

Aizer, A., 2010. The gender wage gap and domestic violence. The American Economic Review 100 (4), 1847.

Aizer, A., Dal Bó, P., 2009. Love, hate and murder: Commitment devices in violent relationships. Journal of public Economics 93 (3), 412-428.

Alesina, A., Brioschi, B., Ferrara, E. L., 2016. Violence against women: A cross-cultural analysis for africa. NBER Working Paper w21901.

Amaral, S., Bandyopadhyay, S., Sensarma, R., 2015. Employment programmes for the poor and female empowerment: the effect of nregs on gender-based violence in india. Journal of interdisciplinary economics 27 (2), 199-218.

Amaral, S., Bhalotra, S., 2017. Sex ratio and violence committed against women: the long-run effects of sex-selection in india. mimeo.

Amin, M., Islam, A. M., Lopez-Claros, A., 2016. Absent laws and missing women: can domestic violence legislation reduce female mortality?

Anderberg, D., Rainer, H., Wadsworth, J., Wilson, T., 2016. Unemployment and domestic violence: Theory and evidence. The Economic Journal 126 (597), 1947-1979.

Asher, S., Novosad, P., 2015. The impacts of local control over political institutions: Evidence from state splitting in india. Unpublished manuscript. 
Banerjee, A., Chattopadhyay, R., Duflo, E., Keniston, D., Singh, N., 2012. Improving police performance in rajasthan, india: Experimental evidence on incentives, managerial autonomy and training. Tech. rep., National Bureau of Economic Research.

Bayer, P., Hjalmarsson, R., Pozen, D., 2009. Building criminal capital behind bars: Peer effects in juvenile corrections. The Quarterly Journal of Economics 124 (1), 105-147.

Beaman, L., Chattopadhyay, R., Duflo, E., Pande, R., Topalova, P., 2009. Powerful women: does exposure reduce bias? The Quarterly Journal of Economics 124 (4), 1497-1540.

Becker, G. S., 1968. Crime and punishment: An economic approach. In: The economic dimensions of crime. Springer, pp. 13-68.

Bhalotra, S., Clots-Figueras, I., 2014. Health and the political agency of women. American Economic Journal: Economic Policy 6 (2), 164-197.

Bindler, A., Hjalmarsson, R., 2017. Prisons, recidivism and the age-crime profile. Economics Letters 152, $46-49$.

Blair, R. A., Karim, S., Gilligan, M. J., Beardsley, K. C., 2016. Policing ethnicity: Lab-in-the-field evidence on discrimination, cooperation and ethnic balancing in the liberian national police.

Bobonis, G. J., González-Brenes, M., Castro, R., 2013. Public transfers and domestic violence: The roles of private information and spousal control. American Economic Journal: Economic Policy, 179-205.

Borker, G., 2017. Safety first: Perceived risk of street harassment and educational choices of women.

Brollo, F., Troiano, U., 2016. What happens when a woman wins an election? evidence from close races in brazil. Journal of Development Economics 122, 28-45.

Burt, M. R., 1980. Cultural myths and supports for rape. Journal of personality and social psychology $38(2), 217$.

Card, D., Dahl, G. B., 2011. Family violence and football: The effect of unexpected emotional cues on violent behavior. The Quarterly Journal of Economics 126 (1), 103-143.

Chattopadhyay, R., Duflo, E., 2004. Women as policy makers: Evidence from a randomized policy experiment in india. Econometrica 72 (5), 1409-1443. 
Clots-Figueras, I., 2011. Women in politics: Evidence from the indian states. Journal of public Economics $95(7), 664-690$.

Comino, S., Mastrobuoni, G., Nicolò, A., 2016. Silence of the innocents: Illegal immigrants' underreporting of crime and their victimization.

Dahl, G., Kotsadam, A., Rooth, D.-O., 2018. Does integration change gender attitudes? the effect of randomly assigning women to traditionally male teams. Tech. rep., National Bureau of Economic Research.

Department, K. H., 2012. Evaluation of functioning of all women police stations in karnataka. mimeo.

Eckel, C. C., Grossman, P. J., 1998. Are women less selfish than men?: Evidence from dictator experiments. The economic journal 108 (448), 726-735.

Erten, B., Keskin, P., 2016. For better or for worse?: Education and the prevalence of domestic violence in turkey. American Economic Journal: Applied Economics.

Garcia-Moreno, C., Jansen, H. A., Ellsberg, M., Heise, L., Watts, C. H., et al., 2006. Prevalence of intimate partner violence: findings from the who multi-country study on women's health and domestic violence. The Lancet 368 (9543), 1260-1269.

Glynn, A. N., Sen, M., 2015. Identifying judicial empathy: Does having daughters cause judges to rule for women's issues? American Journal of Political Science 59 (1), 37-54.

Greenstone, M., Hanna, R., 2014. Environmental regulations, air and water pollution, and infant mortality in india. The American Economic Review 104 (10), 3038-3072.

Gulesci, S., 2017. Forced migration and attitudes towards domestic violence: Evidence from turkey. Tech. rep., WIDER Working Paper.

Hargreaves, J., Cooper, J., Woods, E., McKee, C., 2016. Police workforce, england and wales, 31 march 2016.

Hjalmarsson, R., 2008. Crime and expected punishment: Changes in perceptions at the age of criminal majority. American Law and Economics Review 11 (1), 209-248. 
Iyengar, R., 2009. Does the certainty of arrest reduce domestic violence? evidence from mandatory and recommended arrest laws. Journal of Public Economics 93 (1), 85-98.

Iyer, L., Mani, A., Mishra, P., Topalova, P., 2012. The power of political voice: Women's political representation and crime in India. American Economic Review, Applied Economics (11-092).

Iyer, L., Reddy, M., 2013. Redrawing the Lines: Did Political Incumbents Influence Electoral Redistricting in the World's Largest Democracy? Harvard Business School.

Kavanaugh, G., Sviatschi, M., Trako, I., 2017. Inte-rgenerational benefits of improving access to justice for women: Evidence form peru. Tech. rep., mimeo.

Matsa, D. A., Miller, A. R., 2013. A female style in corporate leadership? evidence from quotas. American Economic Journal. Applied Economics 5 (3), 136.

McDougal, L., Krumholz, S., Bhan, N., Bharadwaj, P., Raj, A., 2018. Releasing the tide: how has a shock to the acceptability of gender-based sexual violence affected rape reporting to police in india? Journal of interpersonal violence, 0886260518811421.

Miller, A. R., Segal, C., 2014. Do female officers improve law enforcement quality? effects on crime reporting and domestic violence escalation.

Natarajan, M., 2016. Women police in a changing society: Back door to equality. Routledge.

Pattavina, A., Buzawa, E., Hirschel, D., Faggiani, D., 2007. Policy, place, and perpetrators: Using nibrs to explain arrest practices in intimate partner violence. Justice Research and Policy 9 (2), 31-51.

Perova, E., Reynolds, S. A., 2017. Women's police stations and intimate partner violence: Evidence from brazil. Social Science \& Medicine 174, 188-196.

Prenzler, T., Sinclair, G., 2013. The status of women police officers: an international review. International Journal of Law, Crime and Justice 41 (2), 115-131.

Secretary-General, U., 2015. Report of the secretary-general on women and peace and security. Tech. rep., United Nations Security Council.

Sekhri, S., Storeygard, A., 2014. Dowry deaths: Response to weather variability in India. Journal of Development Economics 111, 212-223. 
Sherman, L. W., Harris, H. M., 2015. Increased death rates of domestic violence victims from arresting vs. warning suspects in the milwaukee domestic violence experiment (mildve). Journal of experimental criminology 11 (1), 1-20.

Soares, R. R., 2004. Development, crime and punishment: accounting for the international differences in crime rates. Journal of Development Economics 73 (1), 155-184.

Telegraph, T., 2013. Indian rape victim row draws pledge to hire more female police. Tech. rep., The Telegraph.

Tur-Prats, A., 2015. Family types and intimate-partner violence: A historical perspective. Working Paper.

Wagner, N., Rieger, M., Bedi, A., Hout, W., 2017. Gender and policing norms: Evidence from survey experiments among police officers in uganda. Journal of African Economies, 1-24. 
Figure 1: Trend in Reports by Crime Type
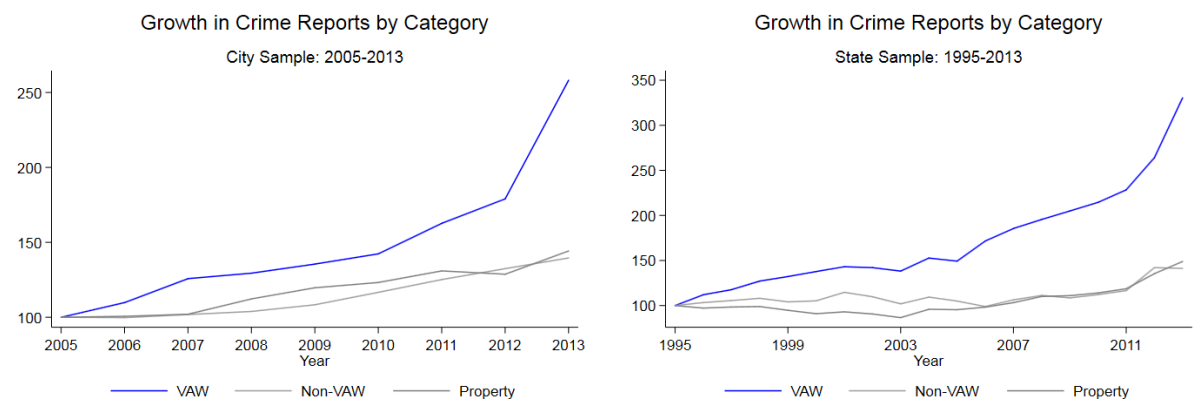

Notes: Trend in reports violence against women (VAW); non-gender based violence (Non-VAW) and property crimes. The left-panel uses the sample of cities and the right-panel the sample of states. The y-axis presents the change in the crime rate from the base year of 2005 and 1995, respectively.

Figure 2: Police Strength and Female Strength by Rank
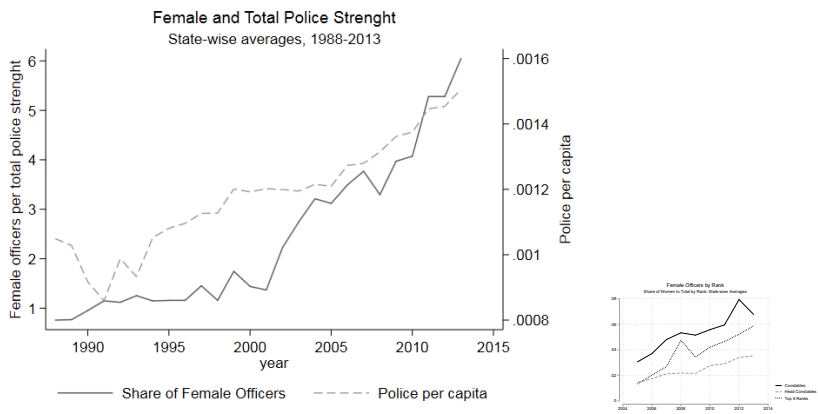

Notes: The left figure presents the trend in the ratio of actual female police strength to total by state-year (left) and total police strength per 100,000 population (right axis). The right-figure presents the share of women in top ranks of police (these are Director of Intelligence Bureau, Commissions of Police or Director General of Police, Joint Commissioner of Police, Additional Commissioner of Police, Deputy Commissioner of Police, Superintendent of Police and Additional Superintendent); as inspectors (there is Inspector, Assistant or Sub-Inspector) and as Head Constable and Constables. Data of policing by gender and rank is only available from 2005. 
Figure 3: Distribution of cities with a woman police station in 2005 and in 2013
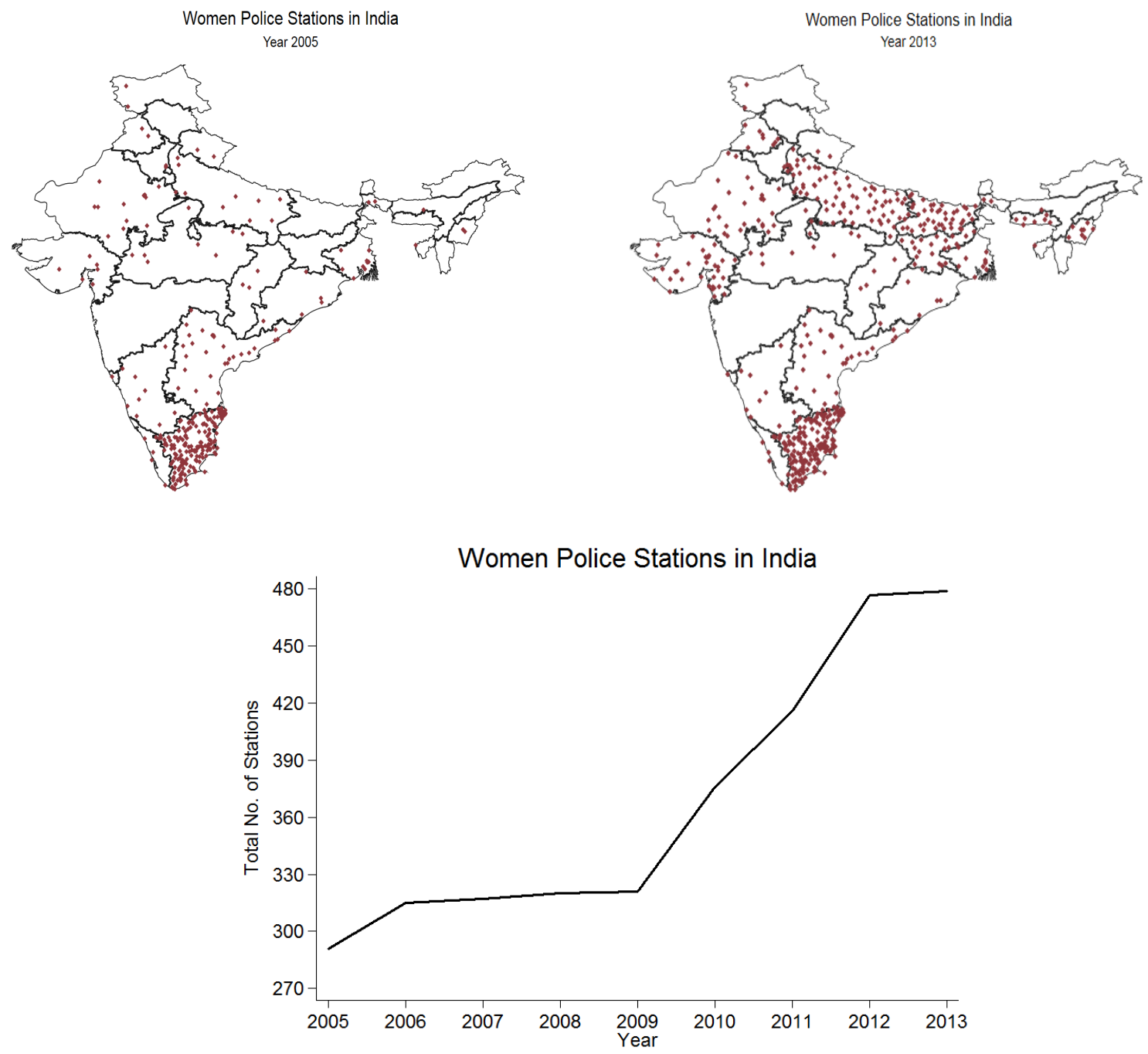

Notes: Each dot denotes a city with at least one woman police station. Using data from the Bureau of Police Research and Development, Ministry of Home Affairs, Government of India. 


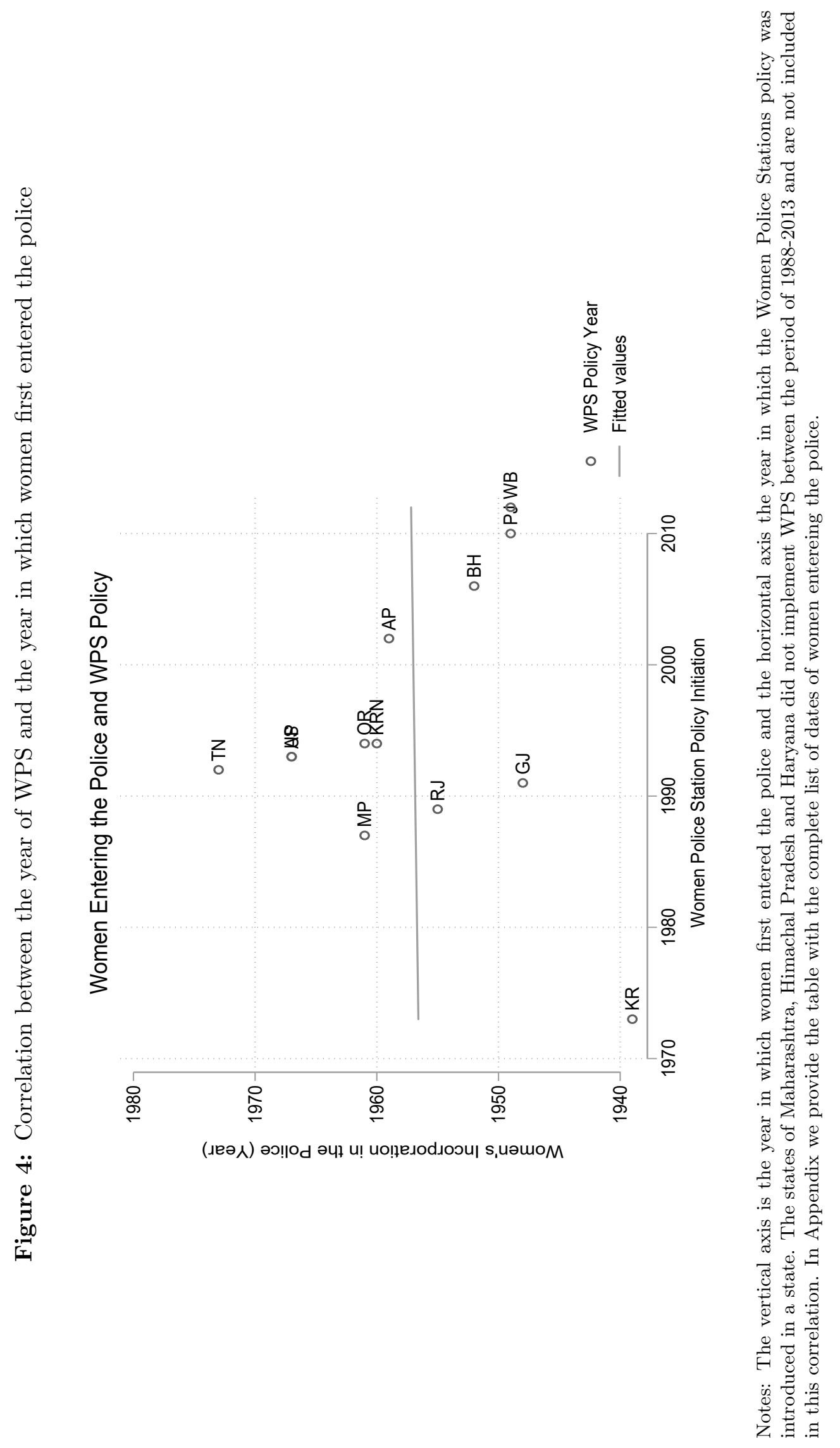


Table 1: Determinants of Placement and Roll-out of WPS in Cities and States

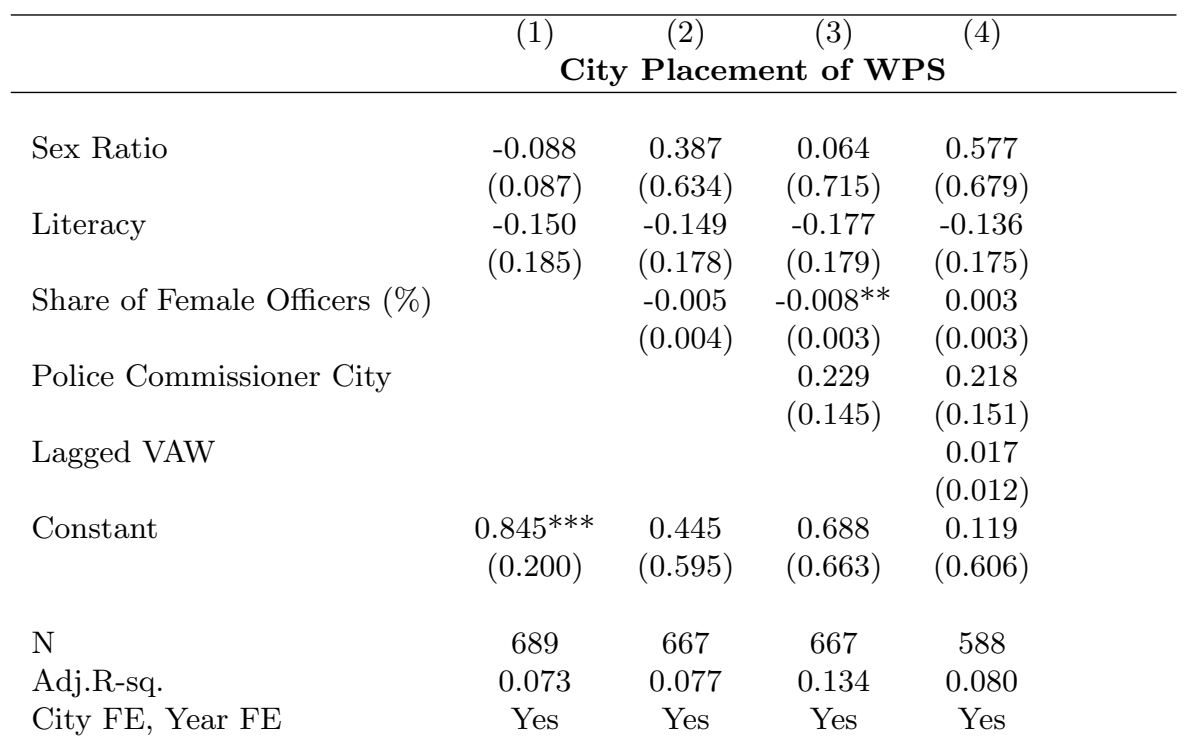

Notes: This dependent variable is a dummy that takes values 1 if in a given city-year a woman station was opened. City level regressions also include a set of city and year dummies. Standard-errors are clustered at the city-level. Significant coefficients are denoted with $* * *$ or $* * *$ if significant at the $1 \%, 5 \%$ or $10 \%$ level. 
Table 2: Determinants of Placement and Roll-out of WPS in Cities and States

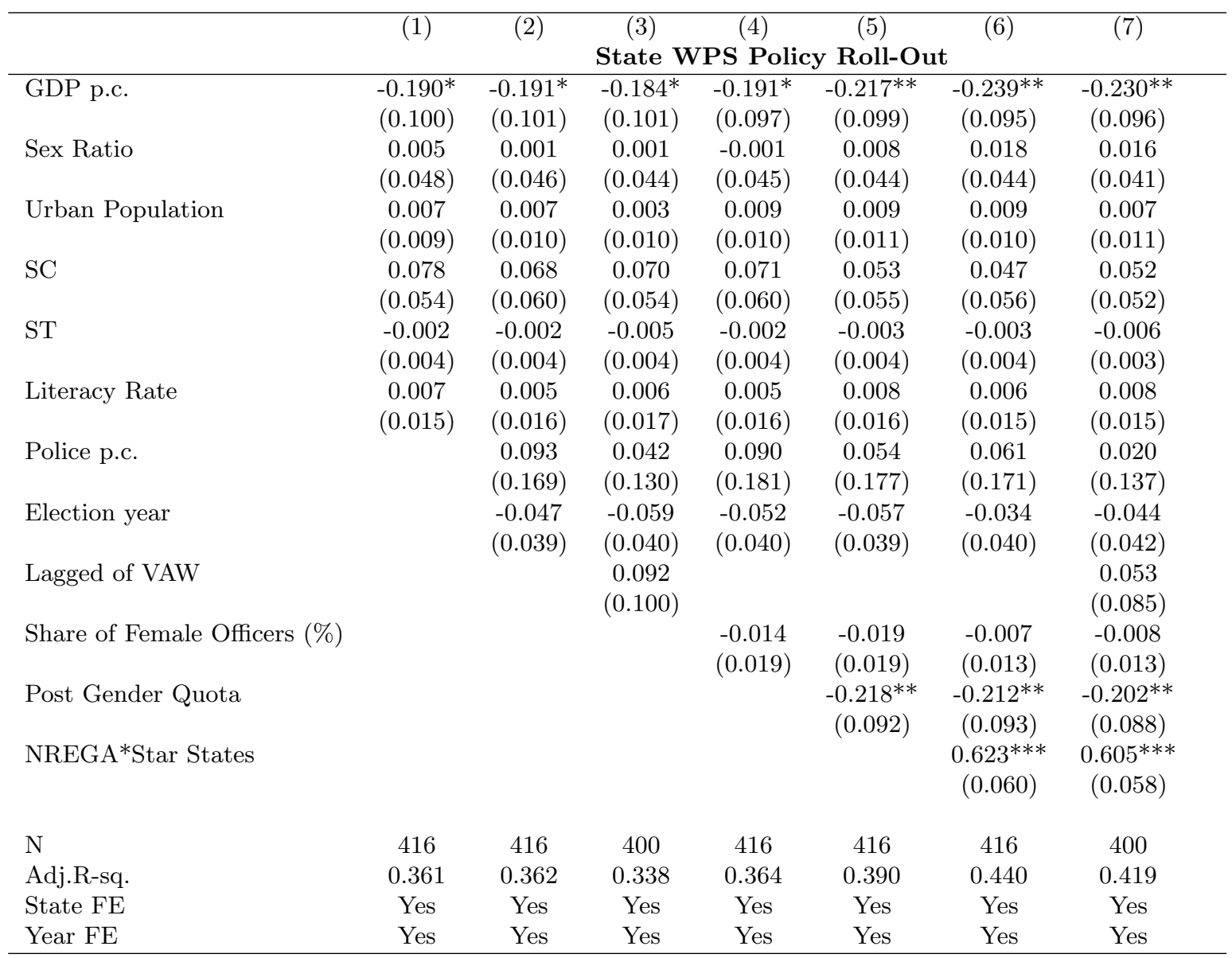

Notes: This dependent variable is a dummy that takes values 1 if in a given state-year. Standard-errors are clustered at the state-level. Significant coefficients are denoted with $* * *$ or $* * *$ if significant at the $1 \%, 5 \%$ or $10 \%$ level. 
Figure 5: Event Study of the Effects of WPS in Cities

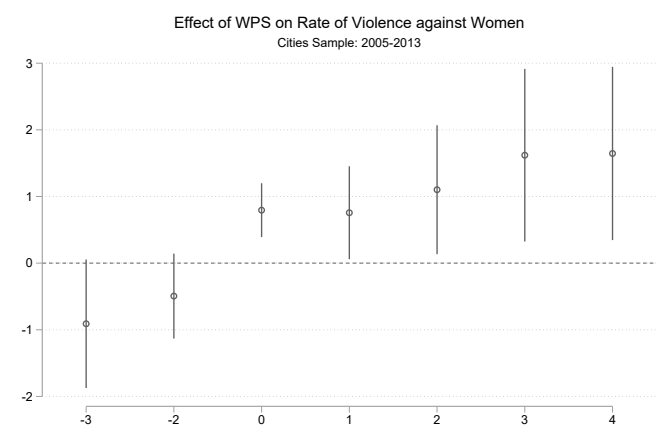

Notes: Coefficients on the time to-since the opening of a police station in cities using as dependent variable the total rate of crimes committed against women. Estimates include city and year fixed-effects and controls for city ratio of females to males and literacy rate a dummy if in a given city-year there is a police commissioner system in place and city-linear trends. The omitted category is year -1 (one year before the policy). Standard errors are clustered at the city-level. All regressions are weighted by population size.

Figure 6: Event Study of the Effects of WPS in States

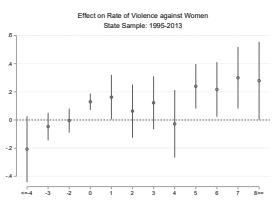

Notes: Coefficients on the time to-since the roll-out of WPS policy in states using as dependent variable the total rate of crimes committed against women. Estimates include state and year fixed-effects, controls for state income per capita, the share of schedules caste and tribe population, literacy rate, sex ratio and dummies for the effects of the gender quotas in local level politics and the implementation of the National Rural Employment Scheme. The omitted category is -1 i.e. 1 year prior to the policy roll-out. Standard-errors are clustered at the state-level. 


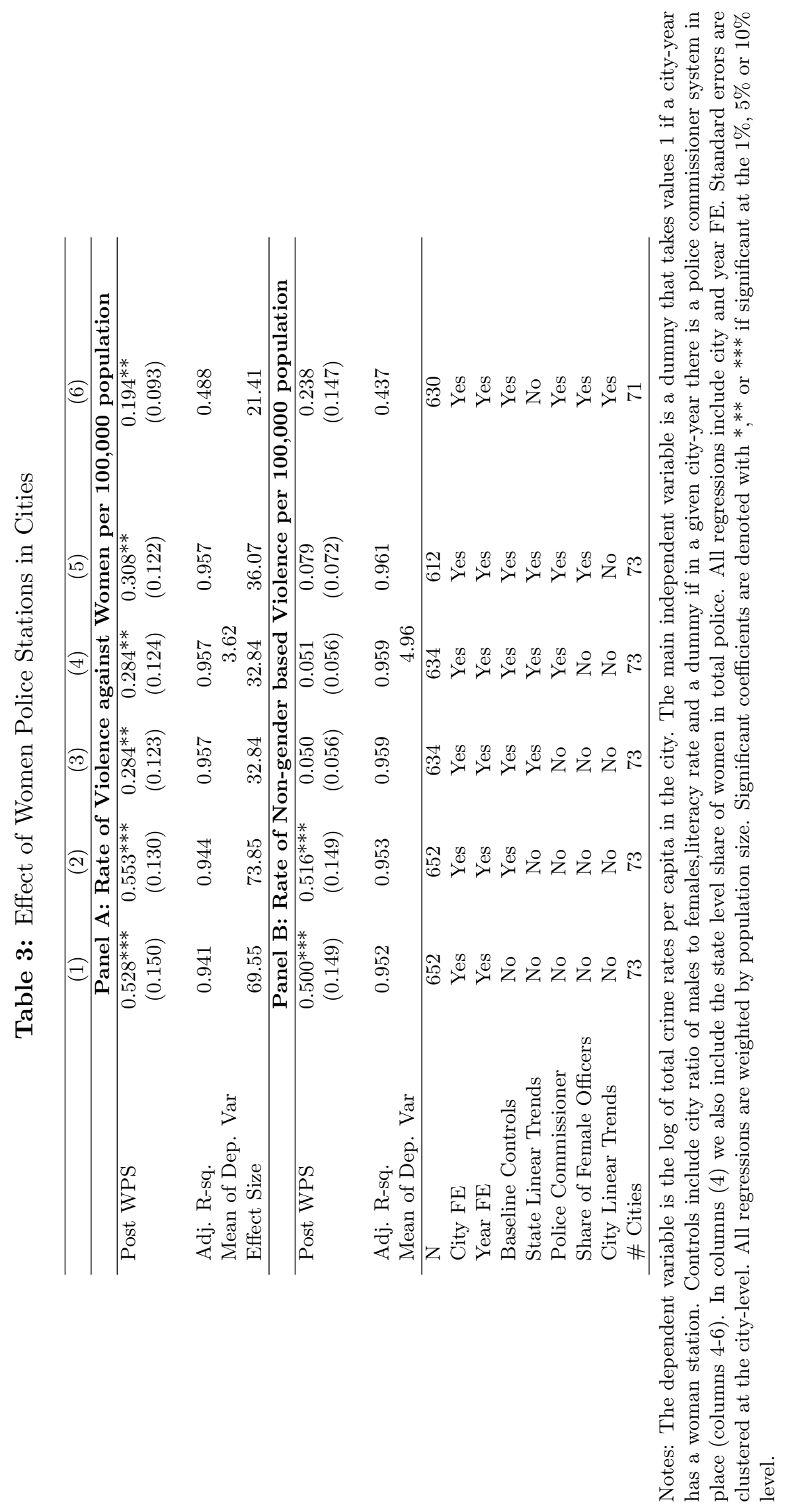




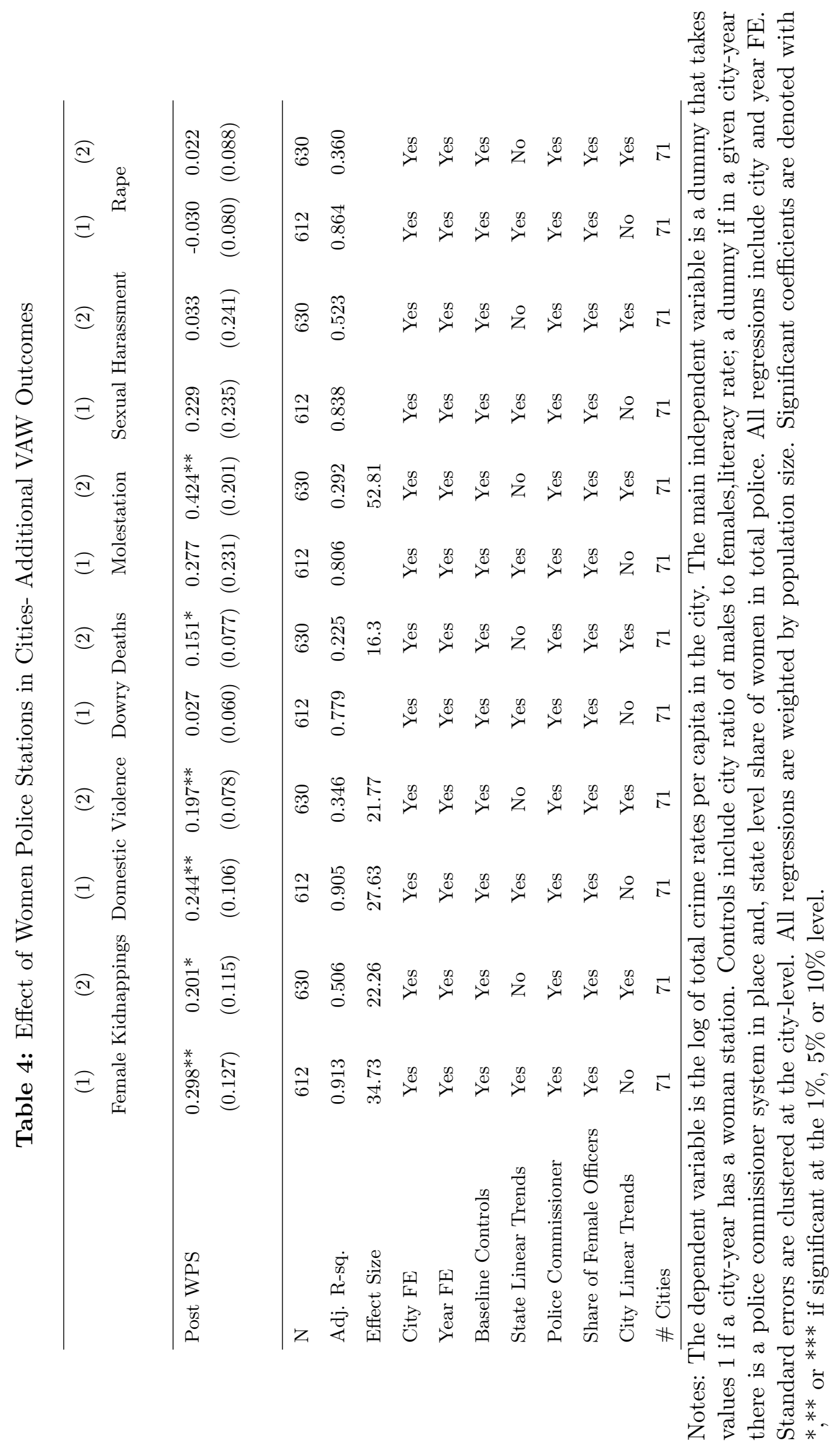




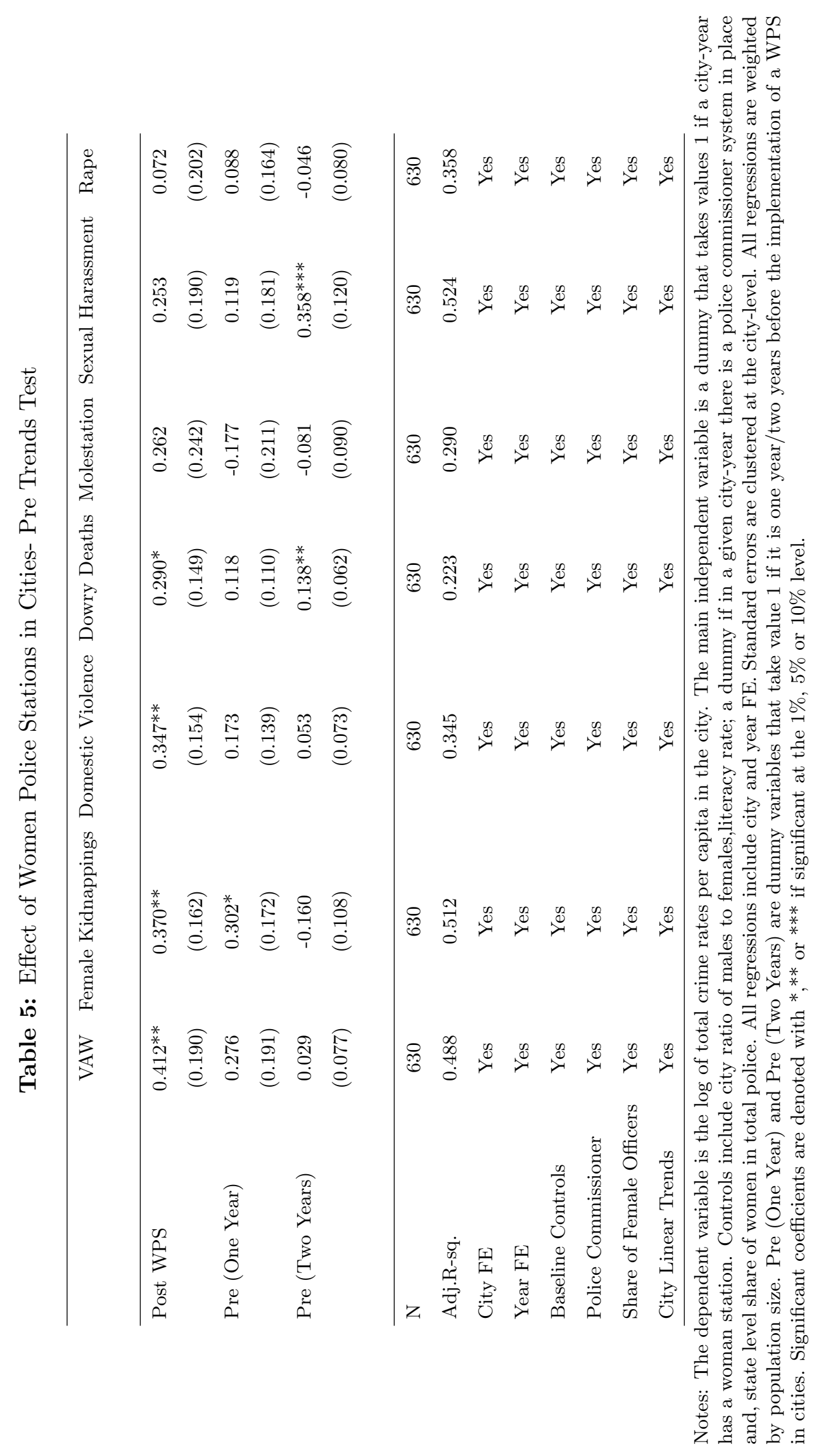


Table 6: Effects of Roll-out of WPS Policy in States

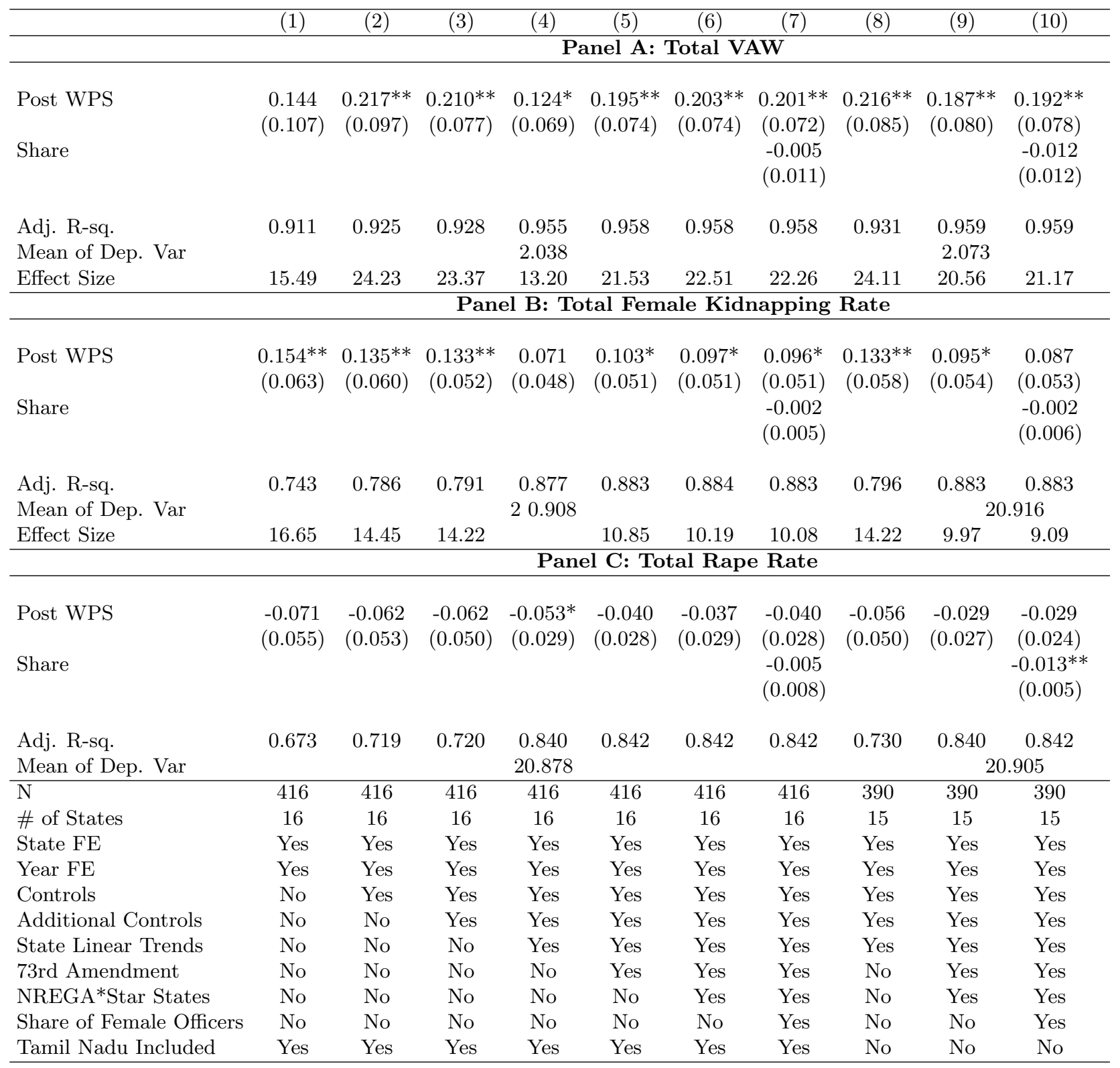

Notes: The dependent variables are the log of crime per 100,000 population. Controls include sex ratio, literacy rate, urban population, share of SC, share of ST, state GDP per capita, police per capita and a dummy for state election years. The Post 73rd Amendment is a dummy that takes values 1 if in a given state-year there are gender quotas for local leadership positions in villages. Share of female officers is theratio of actual female strenght to total police. NREGA*Star States is a dummy that takes values 1 if it is post 2006 and the state is considered to be a good implementor of the NREGA programme. Significant coefficients are denoted with $* * *$ or $* * *$ if significant at the $1 \%, 5 \%$ or $10 \%$ level. 
Table 7: Effect of Women only stations in States- Pre-Trends Test

\begin{tabular}{lcccc}
\hline & $(1)$ & $(2)$ & $(3)$ & $(4)$ \\
& Total & Female Kidnappings & Male Kidnappings & Rape \\
\hline Post WPS Policy & $0.313^{* *}$ & $0.139^{*}$ & 0.046 & -0.006 \\
& $(0.121)$ & $(0.077)$ & $(0.075)$ & $(0.051)$ \\
PostW PSPolicyt-1 & 0.185 & 0.047 & 0.063 & 0.041 \\
& $(0.125)$ & $(0.078)$ & $(0.048)$ & $(0.061)$ \\
PostW PSPolicyt-2 & 0.183 & 0.073 & $0.158^{* *}$ & 0.068 \\
& $(0.118)$ & $(0.064)$ & $(0.070)$ & $(0.064)$ \\
PostW PSPolicyt-3 & 0.145 & 0.042 & 0.066 & 0.060 \\
& $(0.097)$ & $(0.056)$ & $(0.051)$ & $(0.053)$ \\
& & & & \\
\hline N & 416 & 416 & 416 & 416 \\
\# of States & 16 & 16 & 16 & 16 \\
Adj.R-sq. & 0.959 & 0.883 & 0.619 & 0.843 \\
State FE & Yes & Yes & Yes & Yes \\
Year FE & Yes & Yes & Yes & Yes \\
Controls & Yes & Yes & Yes & Yes \\
Additional Controls & Yes & Yes & Yes & Yes \\
State Linear Trends & Yes & Yes & Yes & Yes \\
73rd Amendment & Yes & Yes & Yes & Yes \\
NREGA*Star States & Yes & Yes & Yes & Yes \\
Share & Yes & Yes & Yes & Yes \\
\hline
\end{tabular}

Notes: The dependent variable is the log of total crime rates per capita in the city. The main independent variable is a dummy that takes values 1 if a city-year has a woman station. Controls include city ratio of females to males and literacy rate. It also includes state level share of women in total police (from columns 3; share of women in the 6 top police rank (from columns 4) and the lag of total non violence against women crime in the city. All regressions include city and year FE. Standard errors are clustered at the state-level. Significant coefficients are denoted with $* * *$ or $* * *$ if significant at the $1 \%$, $5 \%$ or $10 \%$ level. 


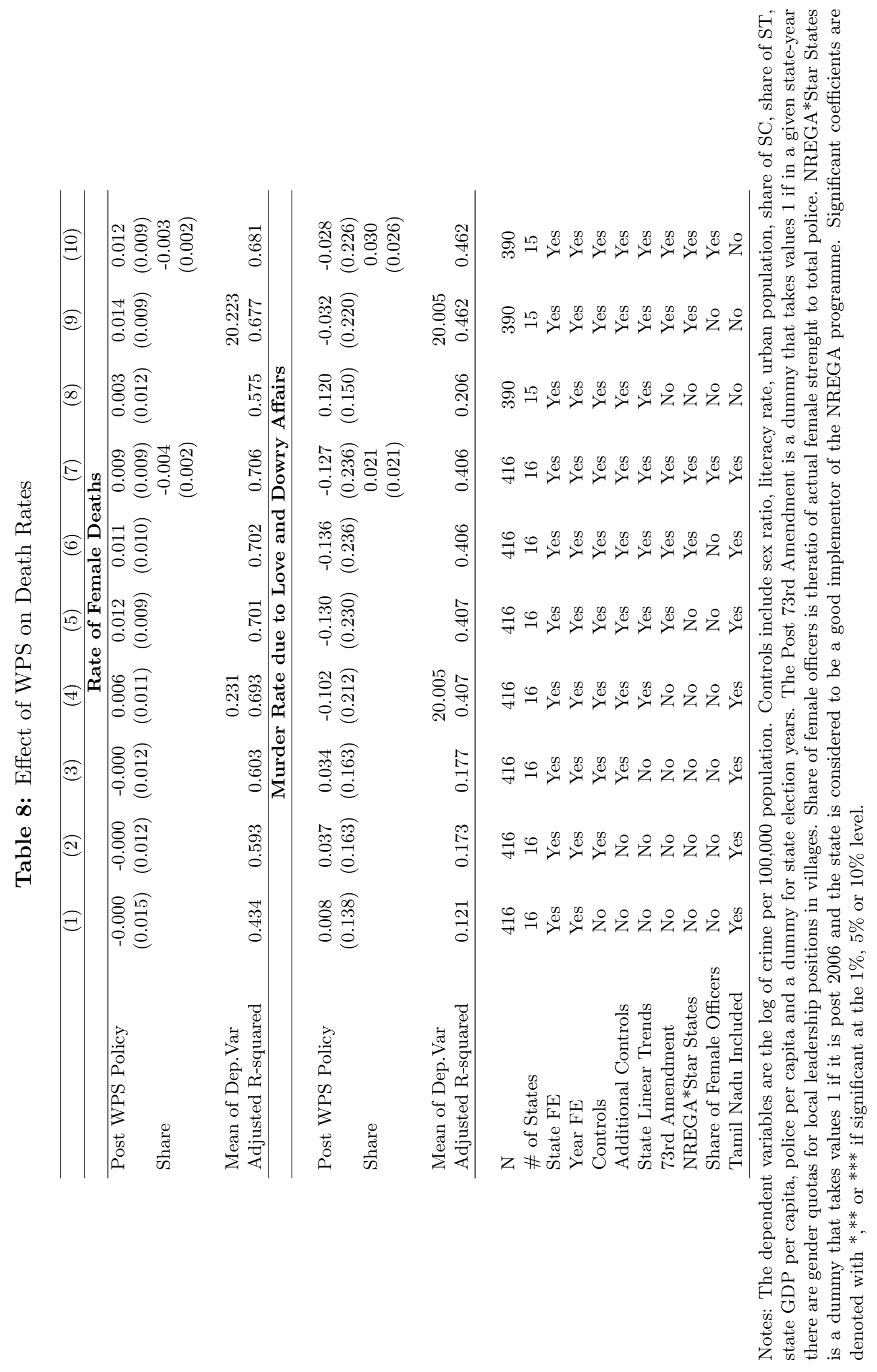




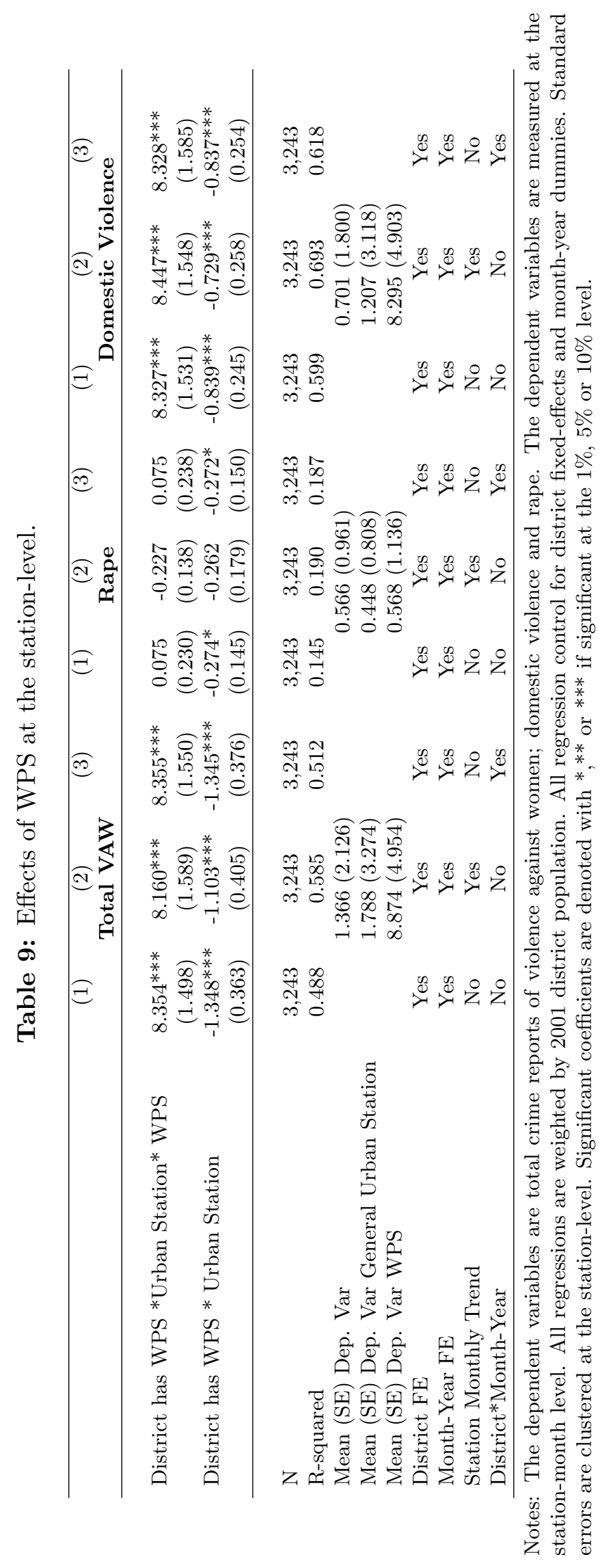




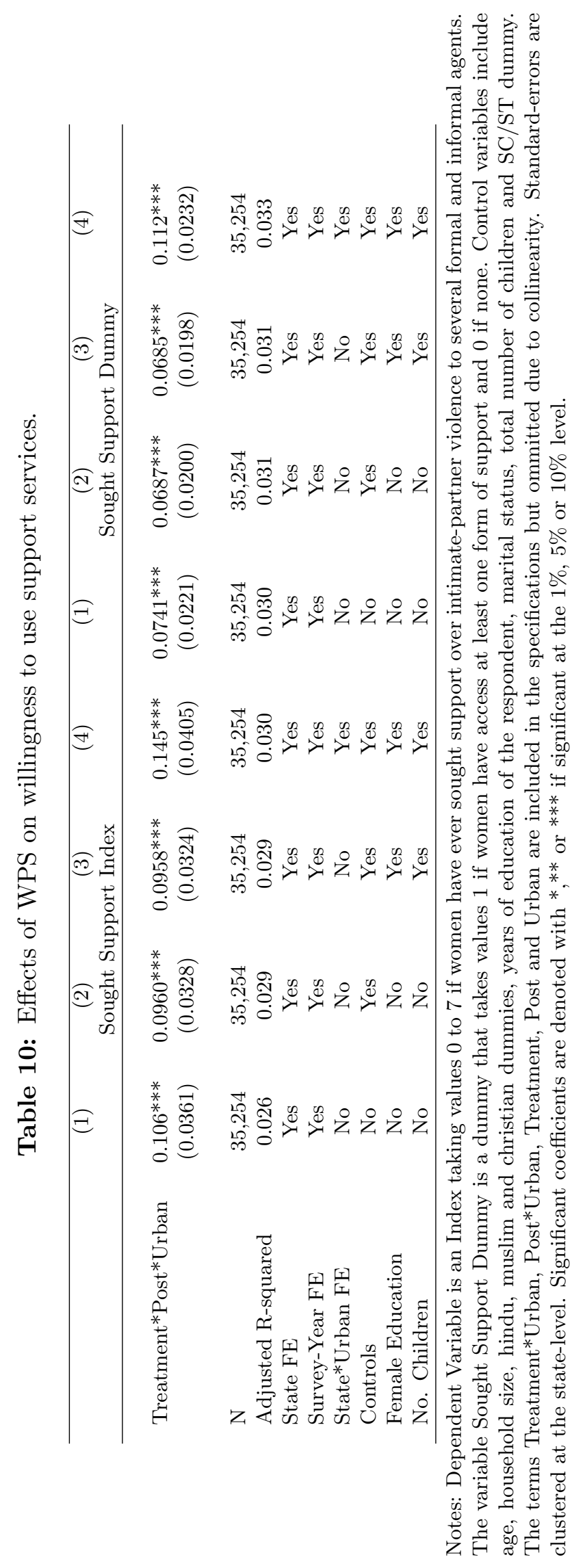




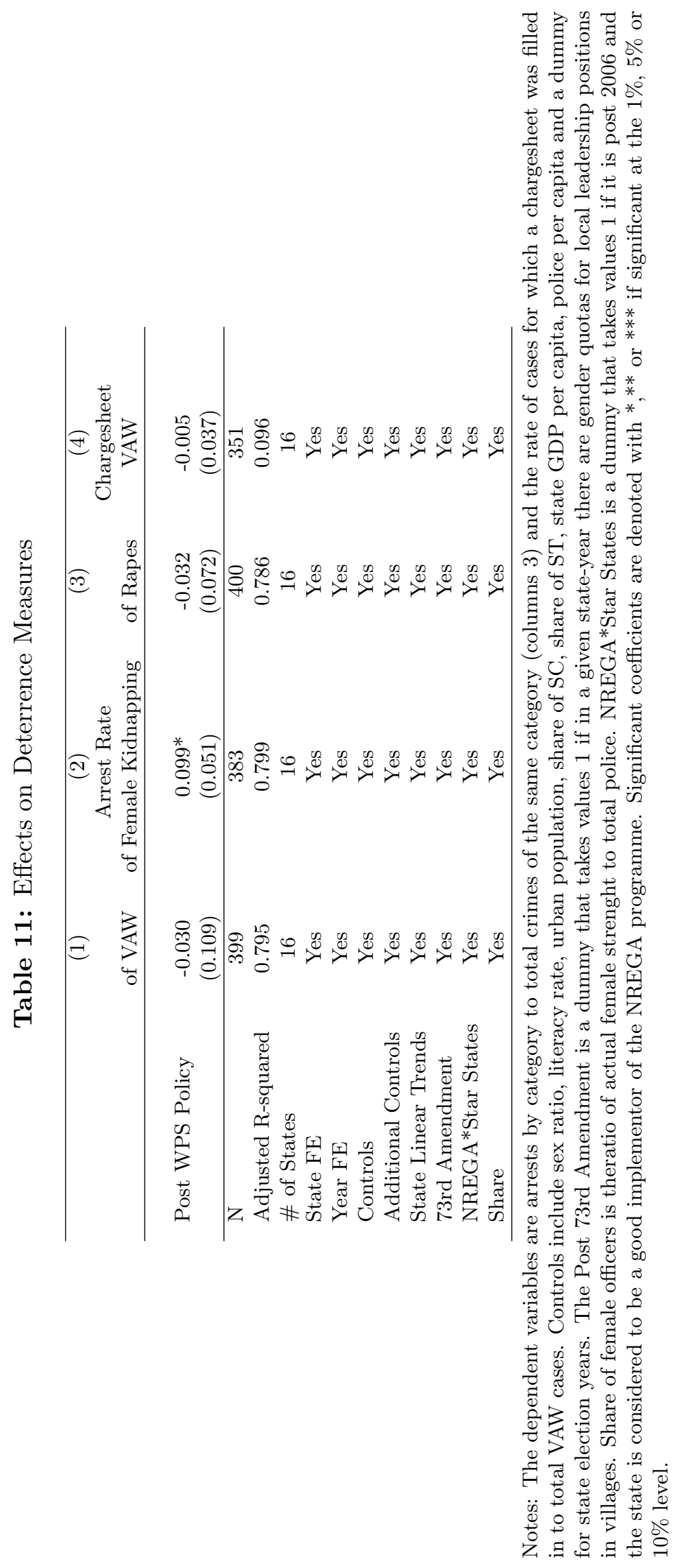




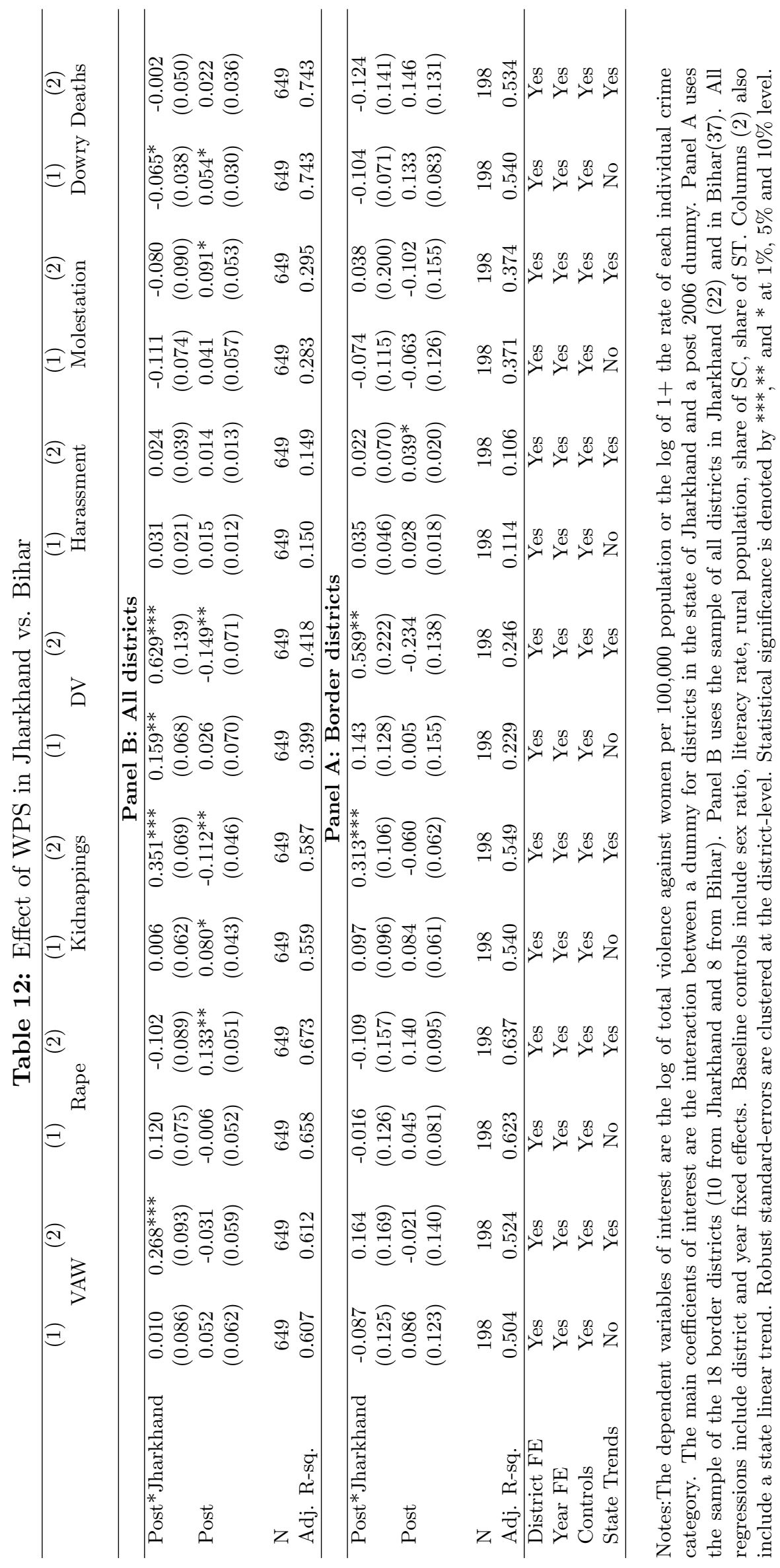




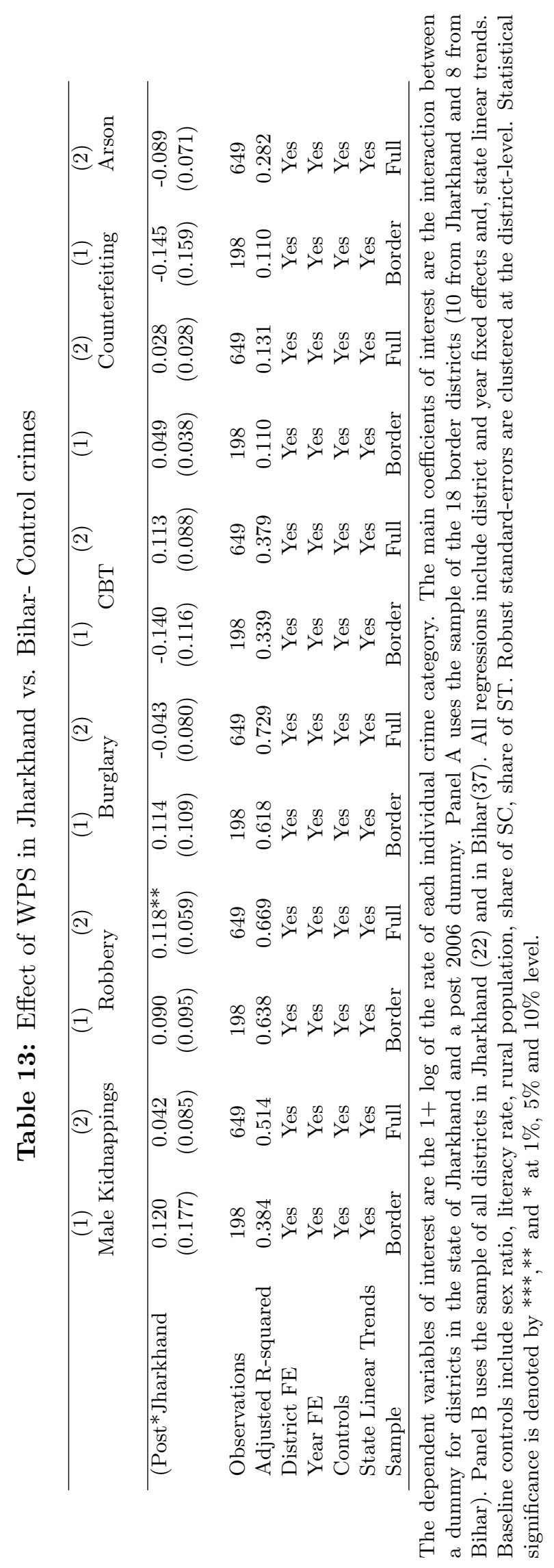


Online Appendix to Gender, Crime and Punishment: The effects of Women Police Stations in India 
Table 14: Women in the Police and Women-only Stations by State

\begin{tabular}{lccc}
\hline State & Year Women Entered the Police & Year WPS Implemented & Share of Women \\
\hline Tamil Nadu & 1973 & 1992 & 5.871 \\
Maharashtra & 1939 & 0 & 4.244 \\
Himachal Pradesh & 1966 & 2014 & 3.150 \\
Karnataka & 1960 & 1994 & 3.020 \\
Kerala & 1939 & 1973 & 3.015 \\
Orissa & 1961 & 1994 & 2.982 \\
Rajasthan & 1955 & 1989 & 2.326 \\
Gujarat & 1948 & 1991 & 2.168 \\
Madhya Pradesh & 1961 & 1987 & 2.111 \\
Haryana & 1966 & 2015 & 2.016 \\
Punjab & 1949 & 2010 & 1.981 \\
Uttar Pradesh & 1967 & 1993 & 1.620 \\
Andhra Pradesh & 1959 & 2002 & 1.520 \\
West Bengal & 1949 & 2012 & 1.469 \\
Bihar & 1952 & 2006 & 1.227 \\
Assam & 1967 & 1993 & 0.491 \\
\hline
\end{tabular}

Notes: This tables presents by state the year in which women were first employed in the law and order; the year in which WPS were implemented and the average sharee of women in the police over the period 1988-2013. Note the geographic boundaries of the states are with respect to pre 2001 boundaries. Table sorted by average share of female officers in states (column 3). 
Table 15: Distribution of women-only police stations by year-state

\begin{tabular}{lccccccccc}
\hline & 2005 & 2006 & 2007 & 2008 & 2009 & 2010 & 2011 & 2012 & 2013 \\
\hline Andhra Pradesh & 25 & 25 & 25 & 25 & 25 & 29 & 31 & 32 & 32 \\
Assam & 1 & 1 & 1 & 1 & 1 & 1 & 1 & 1 & 1 \\
Bihar & 0 & 0 & 0 & 0 & 0 & 0 & 0 & 40 & 40 \\
Chhattisgarh & 3 & 3 & 3 & 3 & 3 & 4 & 4 & 4 & 4 \\
Gujarat & 7 & 7 & 7 & 7 & 8 & 19 & 31 & 31 & 32 \\
Haryana & 1 & 1 & 1 & 1 & 1 & 2 & 2 & 2 & 2 \\
Himachal Pradesh & 0 & 0 & 0 & 0 & 0 & 0 & 0 & 0 & 0 \\
Jammu and Kashmir & 3 & 3 & 3 & 3 & 3 & 2 & 2 & 2 & 2 \\
Jharkhand & 0 & 22 & 22 & 22 & 22 & 22 & 22 & 22 & 22 \\
Karnataka & 10 & 10 & 10 & 10 & 10 & 10 & 10 & 10 & 10 \\
Kerala & 3 & 3 & 3 & 3 & 3 & 3 & 3 & 4 & 4 \\
Madhya Pradesh & 9 & 9 & 9 & 9 & 9 & 9 & 9 & 9 & 9 \\
Maharashtra & 0 & 0 & 0 & 0 & 0 & 0 & 0 & 0 & 0 \\
Orissa & 6 & 6 & 6 & 6 & 6 & 6 & 6 & 6 & 6 \\
Punjab & 0 & 0 & 0 & 0 & 0 & 5 & 5 & 6 & 7 \\
Rajasthan & 12 & 11 & 11 & 14 & 14 & 24 & 24 & 29 & 29 \\
Tamil Nadu & 194 & 196 & 196 & 196 & 196 & 196 & 196 & 196 & 196 \\
Uttar Pradesh & 11 & 12 & 12 & 12 & 12 & 42 & 68 & 71 & 71 \\
Uttaranchal & 2 & 2 & 2 & 2 & 2 & 2 & 2 & 2 & 2 \\
West Bengal & 0 & 0 & 0 & 0 & 0 & 0 & 0 & 10 & 10 \\
\hline Total & 291 & 315 & 317 & 320 & 321 & 376 & 416 & 477 & 479 \\
\hline
\end{tabular}

Notes: Table presents the total number of women police stations functionning by state. Data gathered from yearly publications of the Bureau of Police Research and Development, Ministry of Home Affairs, Government of India. 


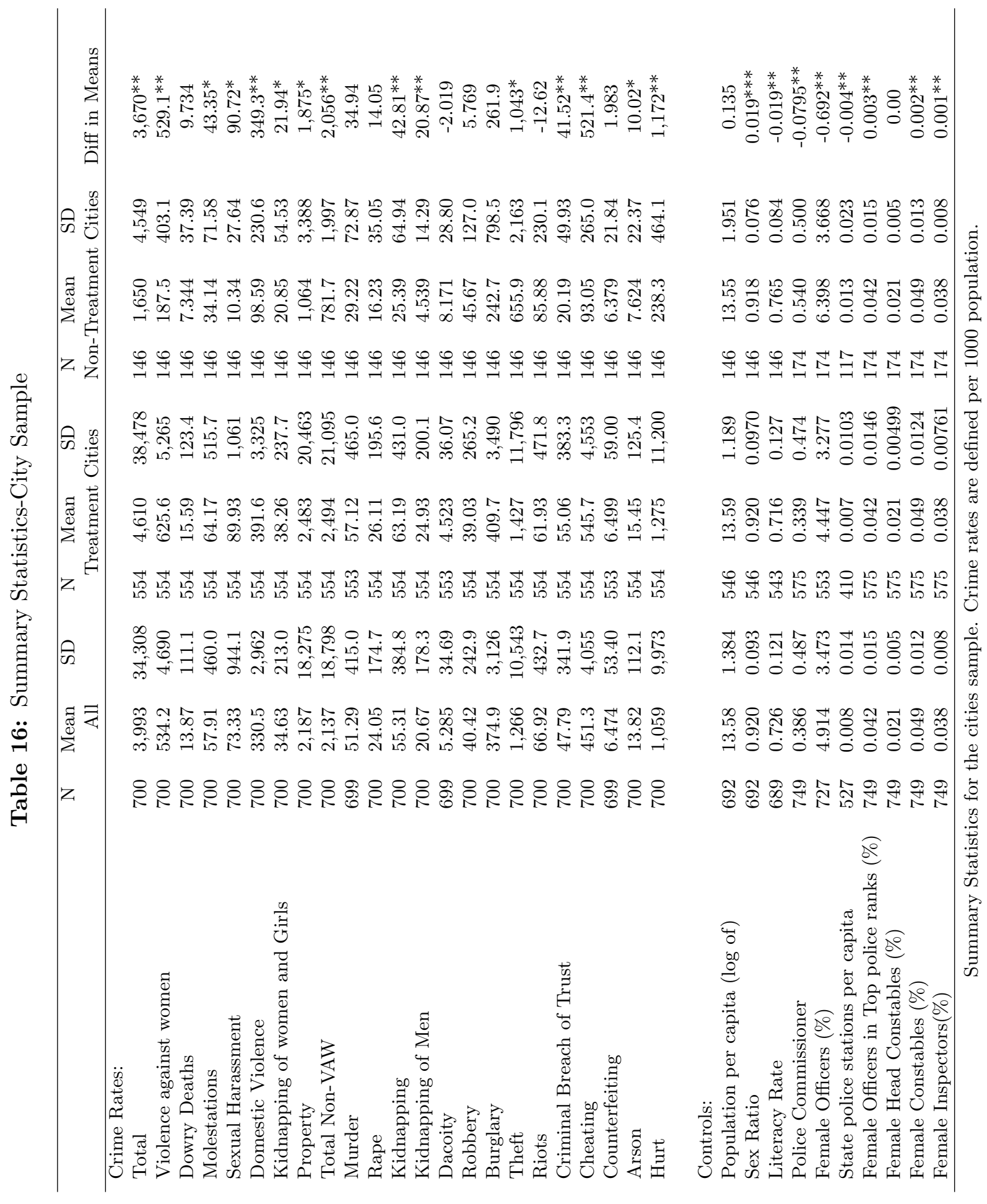


Table 17: Effect of Women only stations in Cities- Additional Non-VAW Outcomes

\begin{tabular}{|c|c|c|c|c|c|c|c|c|c|c|c|c|}
\hline & (1) & $(2)$ & (3) & (4) & (5) & (6) & (1) & $(2)$ & (3) & (4) & (5) & $(6)$ \\
\hline & \multicolumn{6}{|c|}{ Male Kidnappings } & \multicolumn{6}{|c|}{ Hurt } \\
\hline \multirow[t]{2}{*}{ Post WPS } & 0.154 & 0.156 & 0.123 & 0.125 & $0.192^{* *}$ & * 0.098 & $0.827^{* *}$ & $0.809^{* *}$ & 0.033 & 0.032 & 0.080 & 0.515 \\
\hline & $(0.199)$ & $(0.155)$ & $(0.123)$ & $(0.124)$ & $(0.074)$ & $(0.144)$ & $(0.374)$ & $(0.335)$ & $(0.161)$ & $(0.162)$ & $(0.188)$ & $(0.353)$ \\
\hline \multirow[t]{2}{*}{ Adjusted R-squared } & 0.776 & 0.784 & 0.836 & 0.838 & 0.850 & 0.371 & 0.894 & 0.894 & 0.903 & 0.903 & 0.908 & 0.337 \\
\hline & \multicolumn{6}{|c|}{ Robbery } & \multicolumn{6}{|c|}{ Burglary } \\
\hline \multirow[t]{2}{*}{ Post WPS } & $-0.486 * *$ & $-0.475^{* * *}$ & -0.204 & -0.204 & -0.197 & 0.006 & $0.153^{*}$ & 0.169 & 0.254 & 0.255 & 0.238 & 0.105 \\
\hline & $(0.191)$ & $(0.174)$ & $(0.173)$ & $(0.173)$ & $(0.171)$ & $(0.182)$ & $(0.090)$ & $(0.105)$ & $(0.181)$ & $(0.183)$ & $(0.198)$ & $(0.129)$ \\
\hline \multirow[t]{2}{*}{ Adjusted R-squared } & 0.763 & 0.763 & 0.852 & 0.852 & 0.854 & 0.507 & 0.946 & 0.948 & 0.950 & 0.951 & 0.951 & 0.468 \\
\hline & \multicolumn{6}{|c|}{ Thefts } & \multicolumn{6}{|c|}{$\mathrm{CBT}$} \\
\hline \multirow[t]{2}{*}{ Post WPS } & $0.566^{* * *}$ & $0.582^{* * *}$ & 0.137 & 0.138 & 0.154 & 0.195 & $0.265^{*}$ & $0.276^{* *}$ & -0.149 & -0.147 & -0.142 & 0.002 \\
\hline & $(0.123)$ & $(0.132)$ & $(0.134)$ & $(0.136)$ & $(0.130)$ & $(0.164)$ & $(0.152)$ & $(0.130)$ & $(0.178)$ & $(0.180)$ & $(0.179)$ & $(0.085)$ \\
\hline Ad. R-sq. & 0.917 & 0.920 & 0.943 & 0.944 & 0.944 & 0.583 & 0.847 & 0.849 & 0.872 & 0.876 & 0.877 & 0.259 \\
\hline City FE & Yes & Yes & Yes & Yes & Yes & Yes & Yes & Yes & Yes & Yes & Yes & Yes \\
\hline Year FE & Yes & Yes & Yes & Yes & Yes & Yes & Yes & Yes & Yes & Yes & Yes & Yes \\
\hline Baseline Controls & No & Yes & Yes & Yes & Yes & Yes & No & Yes & Yes & Yes & Yes & Yes \\
\hline State Linear Trends & No & No & Yes & Yes & Yes & No & No & No & Yes & Yes & Yes & No \\
\hline Police Commissioner & No & No & No & Yes & Yes & Yes & No & No & No & Yes & Yes & Yes \\
\hline Share & No & No & No & No & Yes & Yes & No & No & No & No & Yes & Yes \\
\hline City Linear Trends & No & No & No & No & No & Yes & No & No & No & No & No & Yes \\
\hline
\end{tabular}

Notes: The dependent variable is the log of total crime rates per capita in the city. The main independent variable is a dummy that takes values 1 if a city-year has a woman station. Controls include city ratio of females to males and literacy rate. It also includes state level share of women in total police (from columns 3; share of women in the 6 top police rank (from columns 4) and the lag of total non violence against women crime in the city. All regressions include city and year FE. Standard errors are clustered at the city-level. 


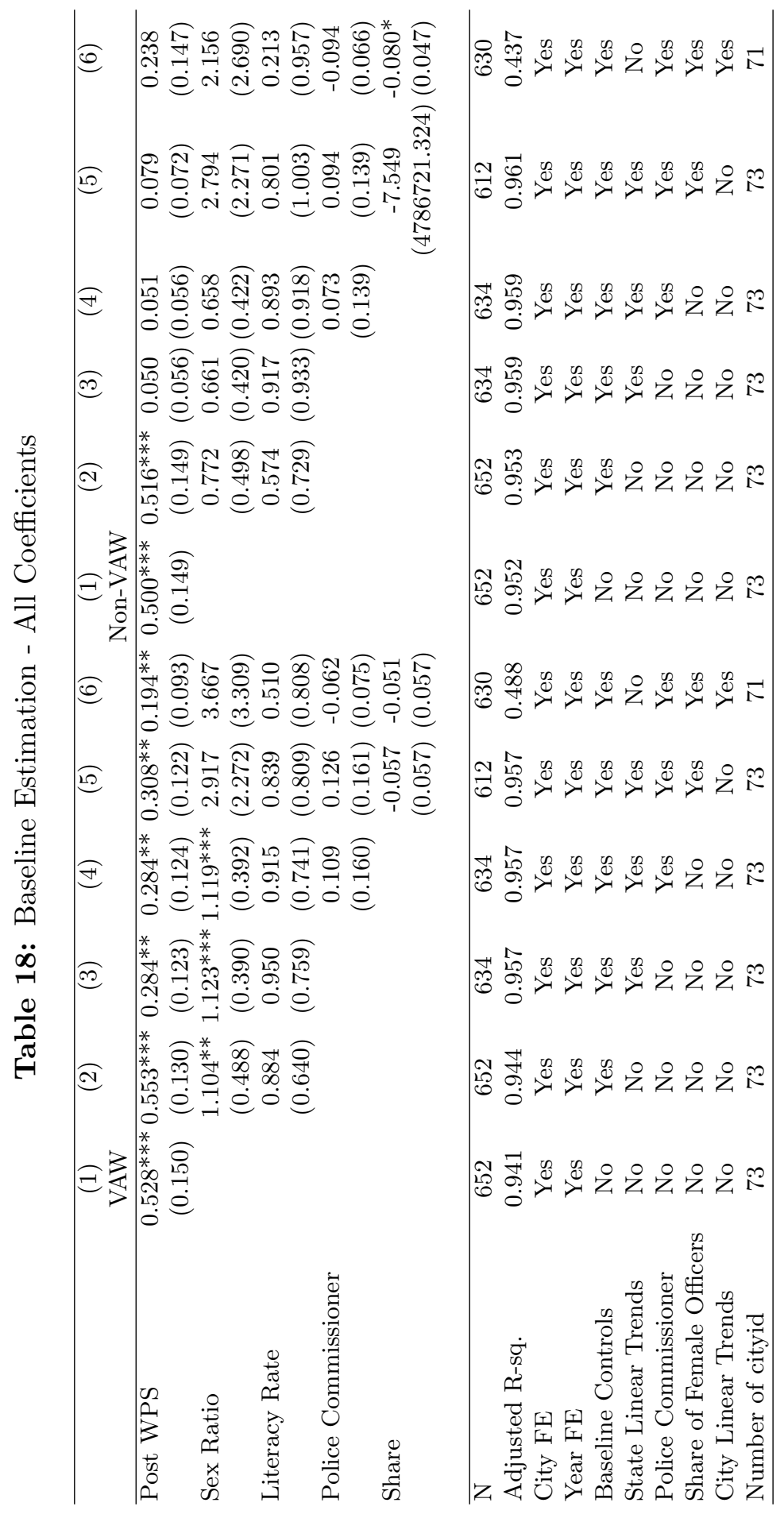




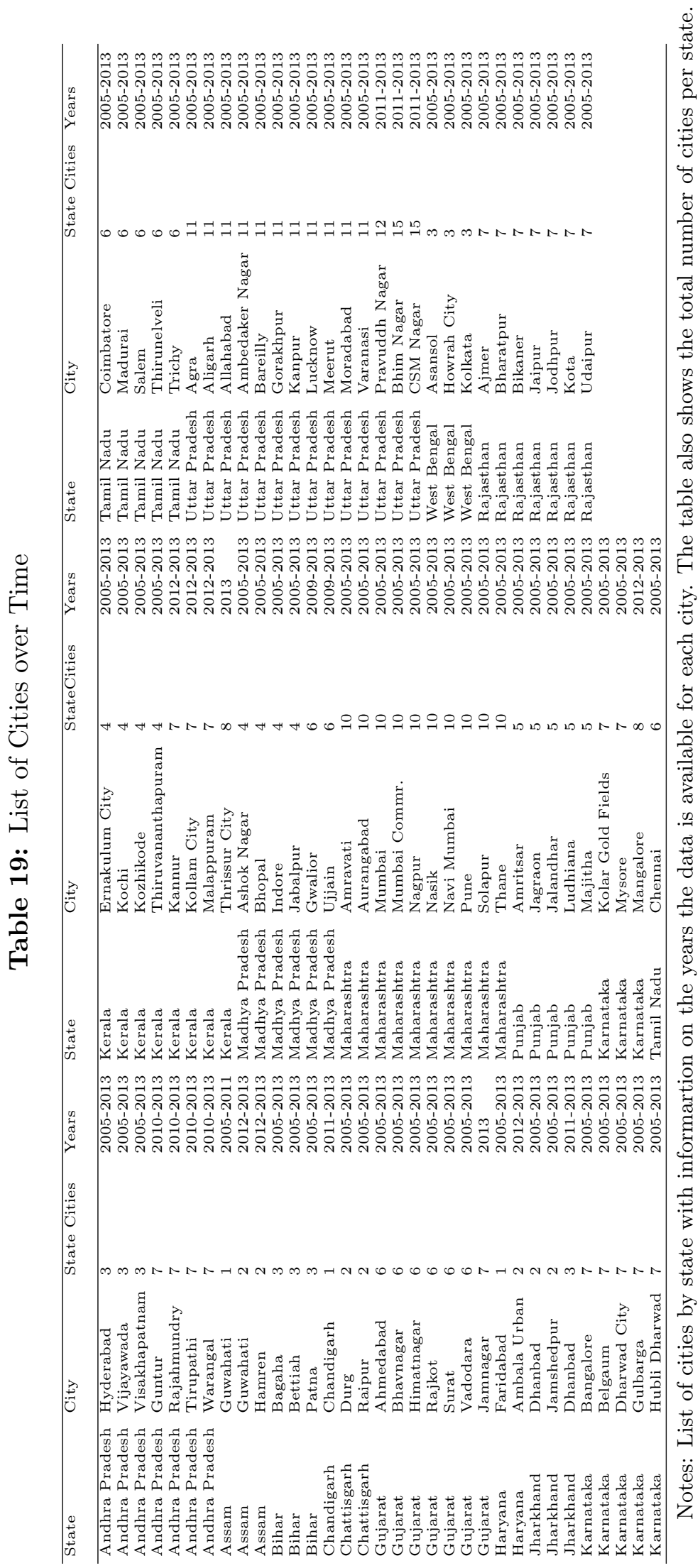




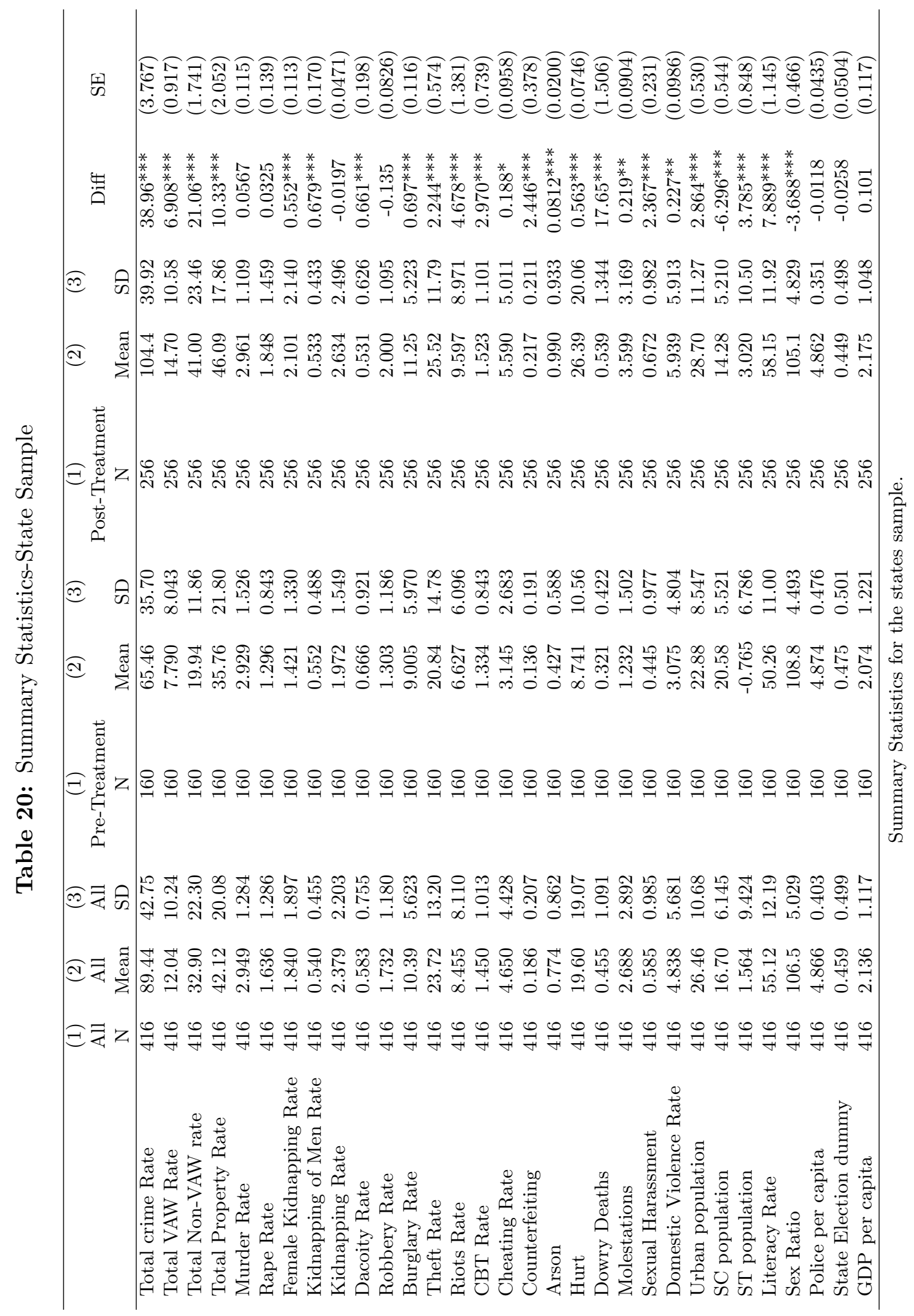


Table 21: Effect of WPS Policy in States- Non-Violence Against Women Coefficients

\begin{tabular}{|c|c|c|c|c|c|c|c|c|c|c|}
\hline & $(1)$ & $(2)$ & $(3)$ & $(4)$ & $(5)$ & $(6)$ & $(7)$ & $(8)$ & $(9)$ & $(10)$ \\
\hline & & \multicolumn{9}{|c|}{ Panel A: Male Kidnappings Rate } \\
\hline \multirow[t]{2}{*}{ Post WPS Policy } & -0.018 & -0.024 & -0.022 & -0.016 & -0.014 & -0.017 & -0.020 & -0.017 & -0.001 & -0.007 \\
\hline & $(0.068)$ & $(0.063)$ & $(0.060)$ & $(0.052)$ & $(0.054)$ & $(0.054)$ & $(0.054)$ & $(0.061)$ & $(0.054)$ & $(0.054)$ \\
\hline Mean of Dep. Var & 0.397 & & & & & & & 0.409 & & \\
\hline \multirow[t]{2}{*}{ Adjusted R-squared } & 0.380 & 0.412 & 0.425 & 0.602 & 0.601 & 0.601 & 0.602 & 0.423 & 0.605 & 0.607 \\
\hline & & \multicolumn{9}{|c|}{ Panel A: Dacoity Rate } \\
\hline \multirow[t]{2}{*}{ Post WPS Policy } & $-0.137^{*}$ & -0.100 & -0.102 & -0.024 & -0.014 & -0.018 & -0.018 & -0.108 & -0.015 & -0.020 \\
\hline & $(0.069)$ & $(0.069)$ & $(0.064)$ & $(0.028)$ & $(0.025)$ & $(0.026)$ & $(0.027)$ & $(0.069)$ & $(0.025)$ & $(0.027)$ \\
\hline Mean of Dep. Var & 0.392 & & & & & & & 0.408 & & \\
\hline \multirow[t]{2}{*}{ Adjusted R-squared } & 0.360 & 0.503 & 0.529 & 0.837 & 0.838 & 0.839 & 0.839 & 0.537 & 0.841 & 0.841 \\
\hline & & \multicolumn{9}{|c|}{ Panel A: Robbery Rate } \\
\hline \multirow[t]{2}{*}{ Post WPS Policy } & -0.082 & -0.040 & -0.041 & -0.039 & -0.025 & -0.025 & -0.026 & -0.031 & -0.011 & -0.010 \\
\hline & $(0.091)$ & $(0.096)$ & $(0.091)$ & $(0.038)$ & $(0.032)$ & $(0.032)$ & $(0.032)$ & $(0.095)$ & $(0.029)$ & $(0.028)$ \\
\hline Mean of Dep. Var & 0.922 & & & & & & & 0.938 & & \\
\hline \multirow[t]{2}{*}{ Adjusted R-squared } & 0.110 & 0.375 & 0.379 & 0.698 & 0.699 & 0.698 & 0.698 & 0.322 & 0.692 & 0.691 \\
\hline & & \multicolumn{9}{|c|}{ Panel A: Burglary Rate } \\
\hline \multirow[t]{2}{*}{ Post WPS Policy } & -0.011 & 0.042 & 0.041 & 0.063 & 0.075 & 0.073 & 0.068 & 0.049 & 0.083 & 0.077 \\
\hline & $(0.064)$ & $(0.048)$ & $(0.045)$ & $(0.049)$ & $(0.049)$ & $(0.051)$ & $(0.049)$ & $(0.046)$ & $(0.053)$ & $(0.050)$ \\
\hline Mean of Dep. Var & 2.278 & & & & & & & 2.287 & & \\
\hline \multirow[t]{2}{*}{ Adjusted R-squared } & 0.396 & 0.574 & 0.573 & 0.696 & 0.697 & 0.696 & 0.698 & 0.584 & 0.707 & 0.711 \\
\hline & \multicolumn{10}{|c|}{ Panel A:Thefts Rate } \\
\hline \multirow[t]{2}{*}{ Post WPS Policy } & 0.091 & 0.077 & 0.076 & 0.084 & 0.096 & 0.095 & 0.086 & 0.068 & 0.089 & 0.079 \\
\hline & $(0.055)$ & $(0.058)$ & $(0.057)$ & $(0.071)$ & $(0.071)$ & $(0.074)$ & $(0.072)$ & $(0.060)$ & $(0.080)$ & $(0.078)$ \\
\hline Mean of Dep. Var & 3.074 & & & & & & & 3.063 & & \\
\hline Adjusted R-squared & 0.375 & 0.393 & 0.391 & 0.570 & 0.571 & 0.570 & 0.576 & 0.451 & 0.583 & 0.592 \\
\hline \multirow[t]{2}{*}{$\mathrm{N}$} & 416 & 416 & 416 & 416 & 416 & 416 & 416 & 390 & 390 & 390 \\
\hline & \multicolumn{10}{|c|}{ Total Male Death Rates } \\
\hline \multirow[t]{2}{*}{ Post WPS Policy } & -0.060 & -0.023 & -0.021 & 0.023 & 0.032 & 0.027 & 0.021 & -0.014 & 0.037 & 0.027 \\
\hline & $(0.047)$ & $(0.038)$ & $(0.038)$ & $(0.029)$ & $(0.027)$ & $(0.026)$ & $(0.023)$ & $(0.040)$ & $(0.028)$ & $(0.024)$ \\
\hline Mean of Dep. Var & 0.570 & & & & & & & 0.556 & & \\
\hline Adjusted R-squared & 0.689 & 0.820 & 0.822 & 0.917 & 0.917 & 0.918 & 0.922 & 0.809 & 0.910 & 0.917 \\
\hline $\mathrm{N}$ & 411 & 411 & 411 & 411 & 411 & 411 & 411 & 386 & 386 & 386 \\
\hline \# of States & 16 & 16 & 16 & 16 & 16 & 16 & 16 & 15 & 15 & 15 \\
\hline State FE & Yes & Yes & Yes & Yes & Yes & Yes & Yes & Yes & Yes & Yes \\
\hline Year FE & Yes & Yes & Yes & Yes & Yes & Yes & Yes & Yes & Yes & Yes \\
\hline Controls & No & Yes & Yes & Yes & Yes & Yes & Yes & Yes & Yes & Yes \\
\hline Additional Controls & No & No & Yes & No & No & No & No & Yes & Yes & Yes \\
\hline State Linear Trends & No & No & No & Yes & No & No & No & No & Yes & Yes \\
\hline 73rd Amendment & No & No & No & No & Yes & Yes & Yes & No & No & Yes \\
\hline NREGA*Star States & No & No & No & No & No & Yes & Yes & No & No & Yes \\
\hline Share & No & No & No & No & No & No & No & No & No & Yes \\
\hline
\end{tabular}

The dependent variables are the log of crime per 100,000 population. Controls include sex ratio, literacy rate, urban population, share of SC, share of ST, state GDP per capita, police per capita and a dummy for state election years. The Post 73rd Amendment is a dummy that takes values 1 if in a given state-year there are gender quotas for local leadership positions in villages. Share of female officers is that ratio of actual female strenght to total police. 


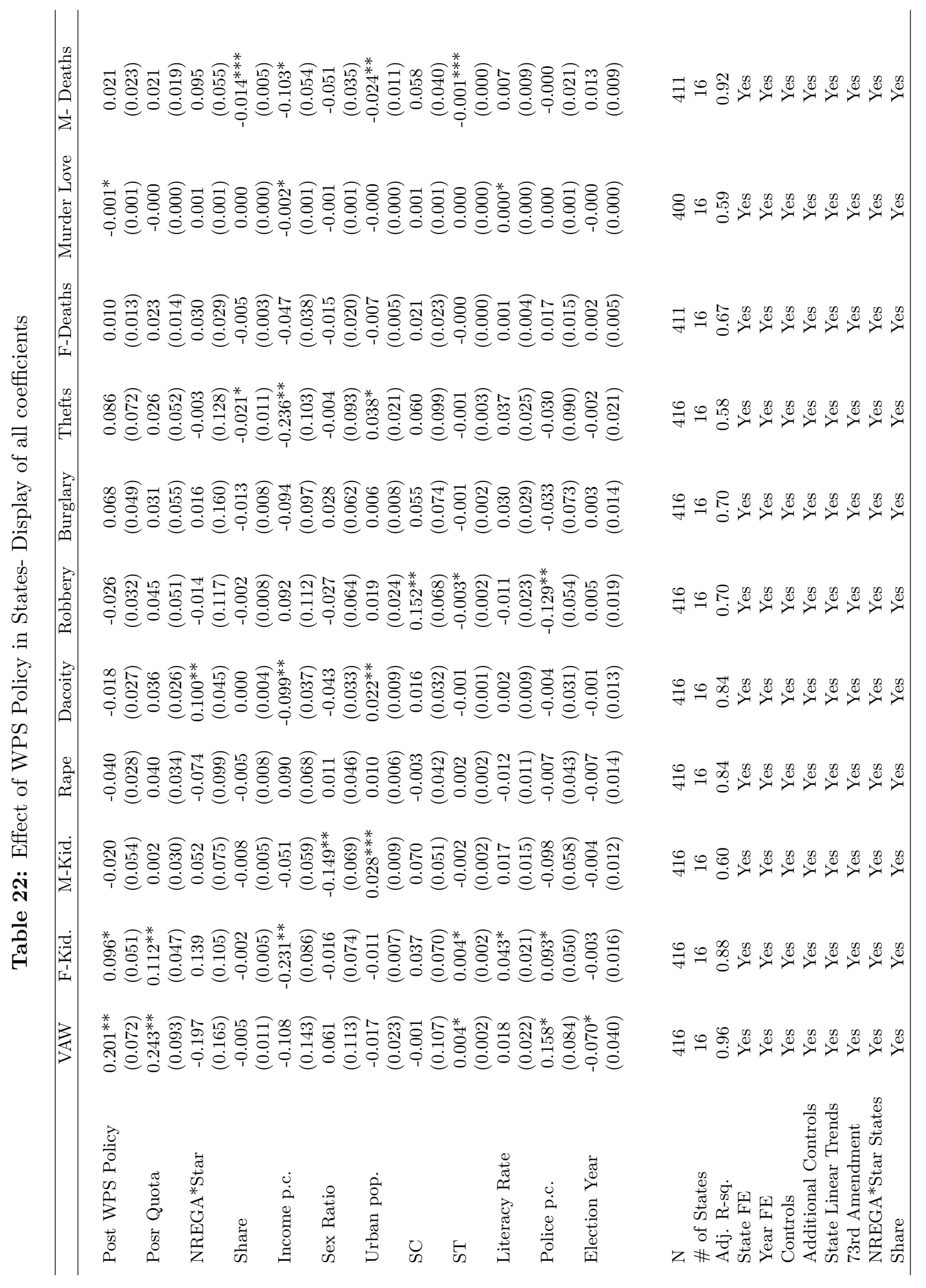




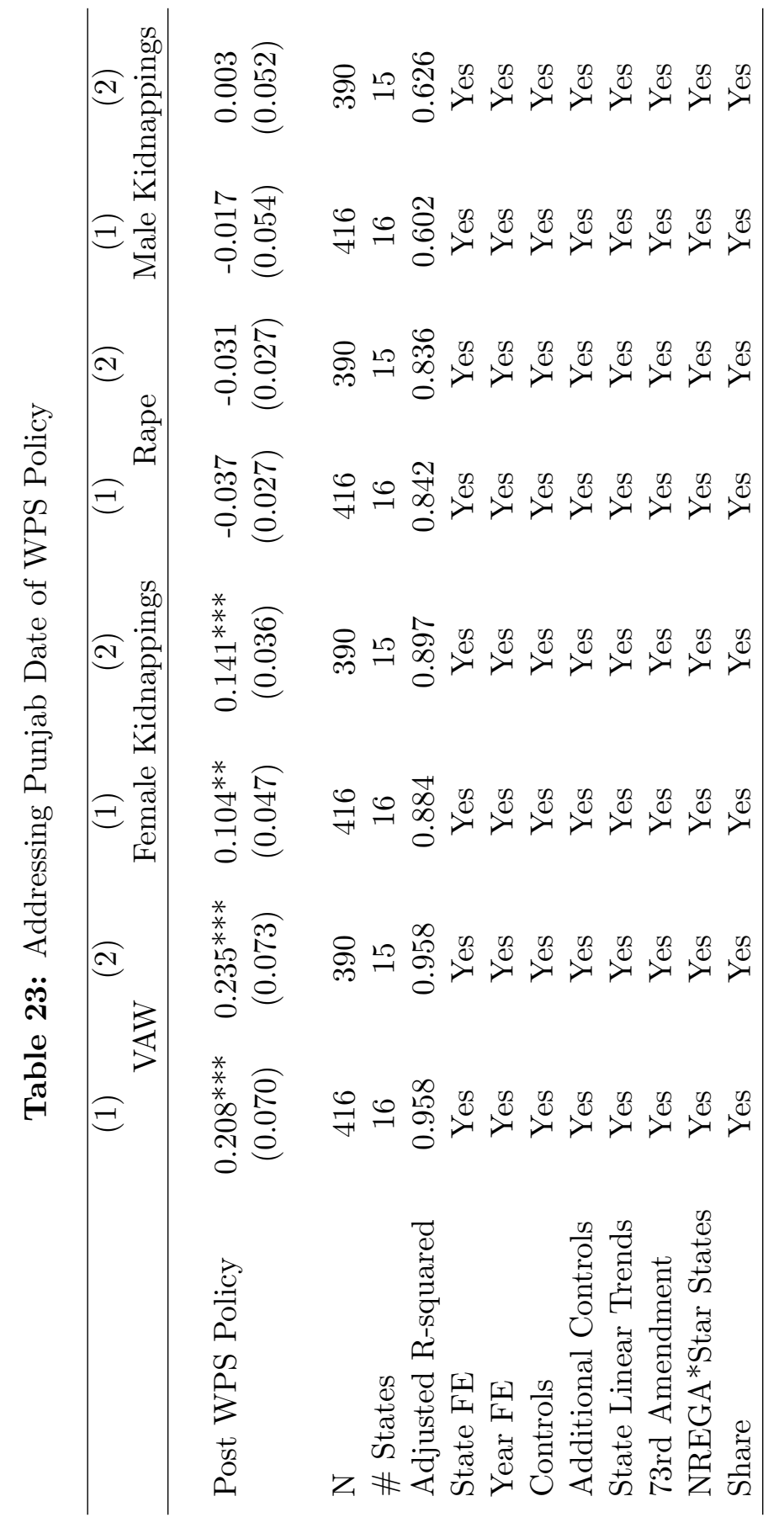


Figure 7: Coefficient Estimates by Iterative Removal of States

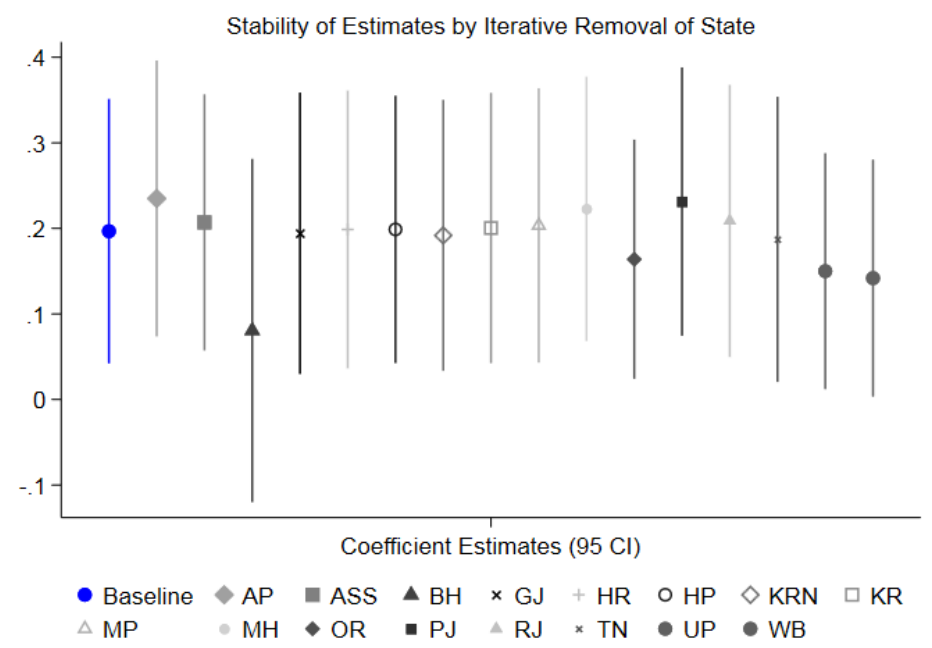

Notes: Coefficient estimates of the effects of the roll-out of the WPS in states. The baseline estimate corresponds to the estimate in Column 7 of Table 6. Each regression estimates the effect of the roll-out of WPS and controls for state and year dummies, sex ratio, literacy rate, share of SC and ST population, income per capita, share of female officers, a dummy for the post $73^{\text {rd }}$ Amendment and a dummy for the post NREGA roll-out in Star States. The labels indicate that the estimate contains all 16 states except the state labelled; e.g. estimate AP contains uses the sample of all 15 states except Andhra Pradesh. The labels refer to AP Andra Pradesh; ASS Assam; BH Bihar; GJ Gujarat; HR Haryana; HP Himachal Pradesh; KRN Karnataka; KR Kerala; MP Madhya Pradesh; MH Maharashtra; OR Orissa; PJ Punjab; RJ Rajasthan; TN Tamil Nadu; UP Uttar Pradesh and WB West Bengal. 


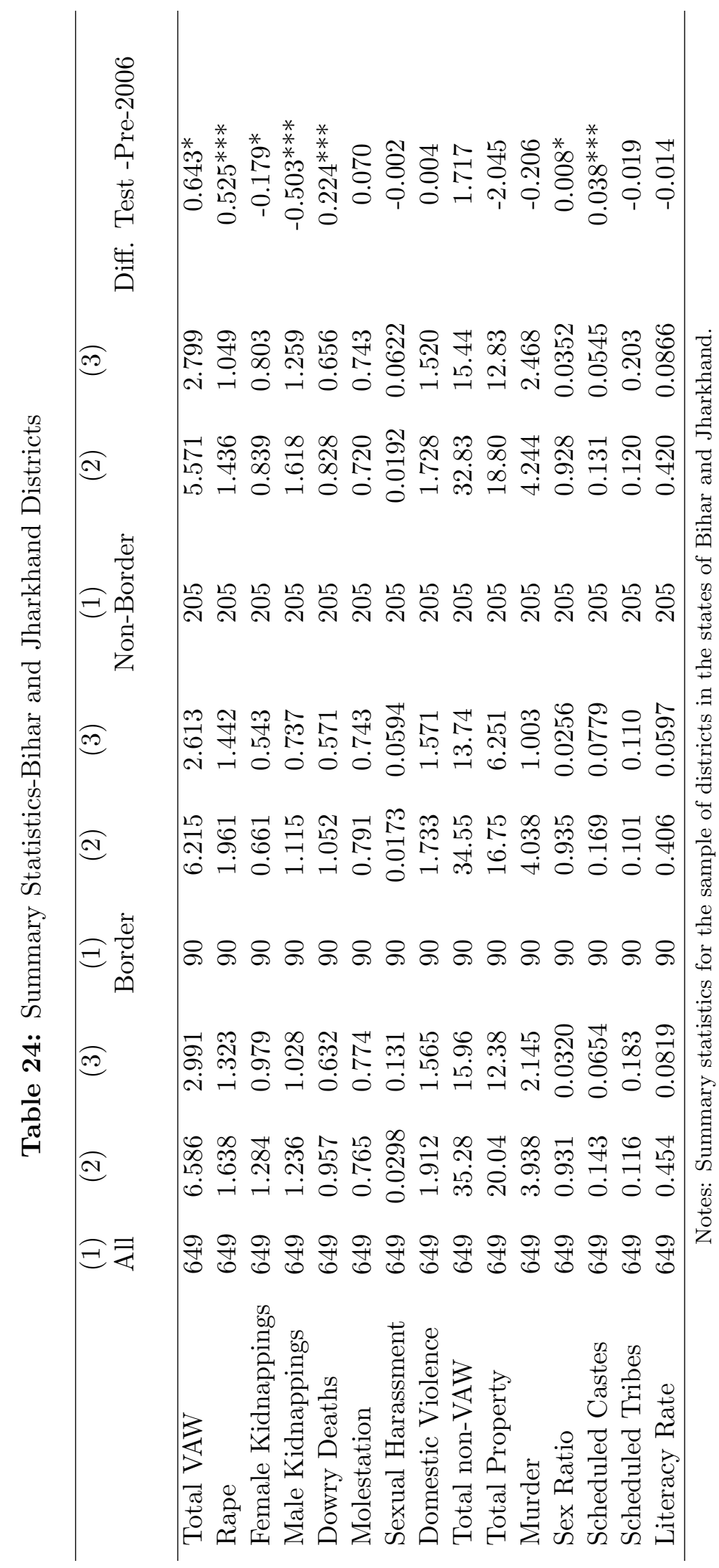


Figure 8: Violence against women across Jharkhand and Bihar Before-After WPS
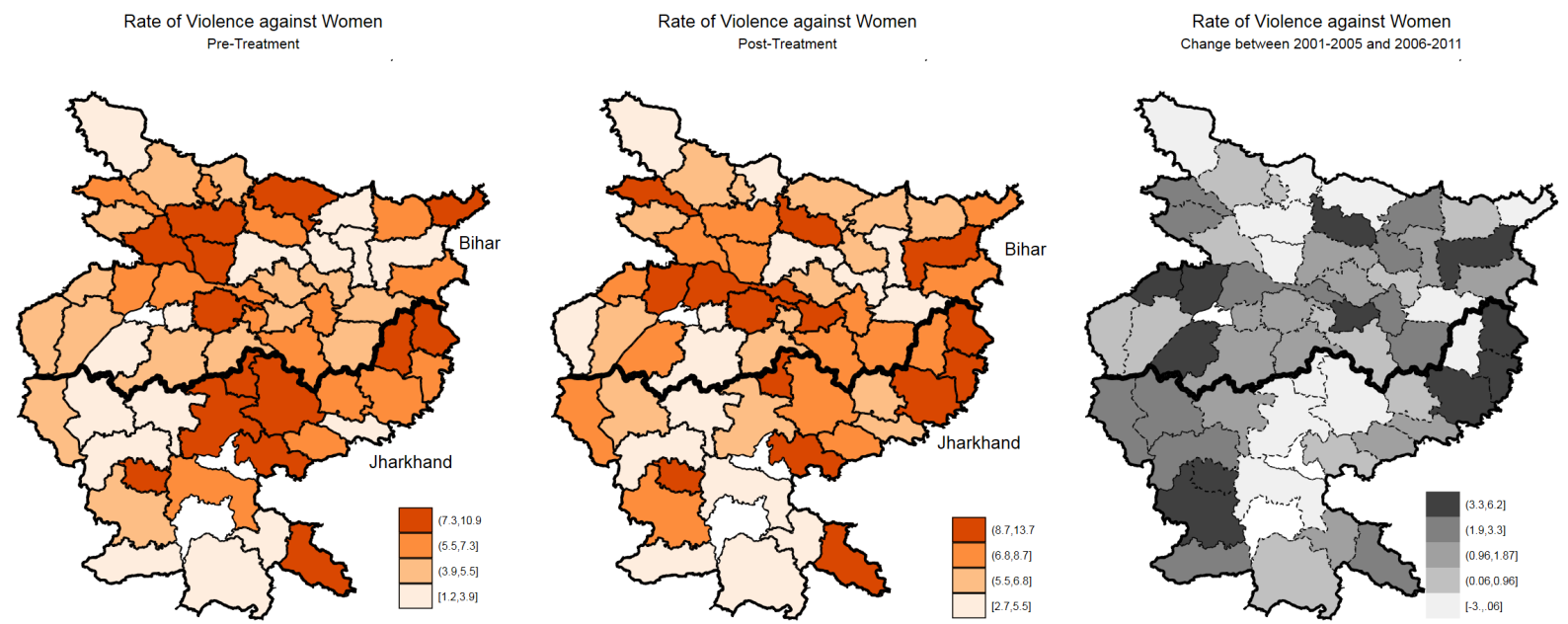

Notes: District means in the rate of total violence committed against women per 1000 population in the years between 2001-2005 (left panel) and in the years between 2005-2011 (central figure). The right panel plots the difference. 


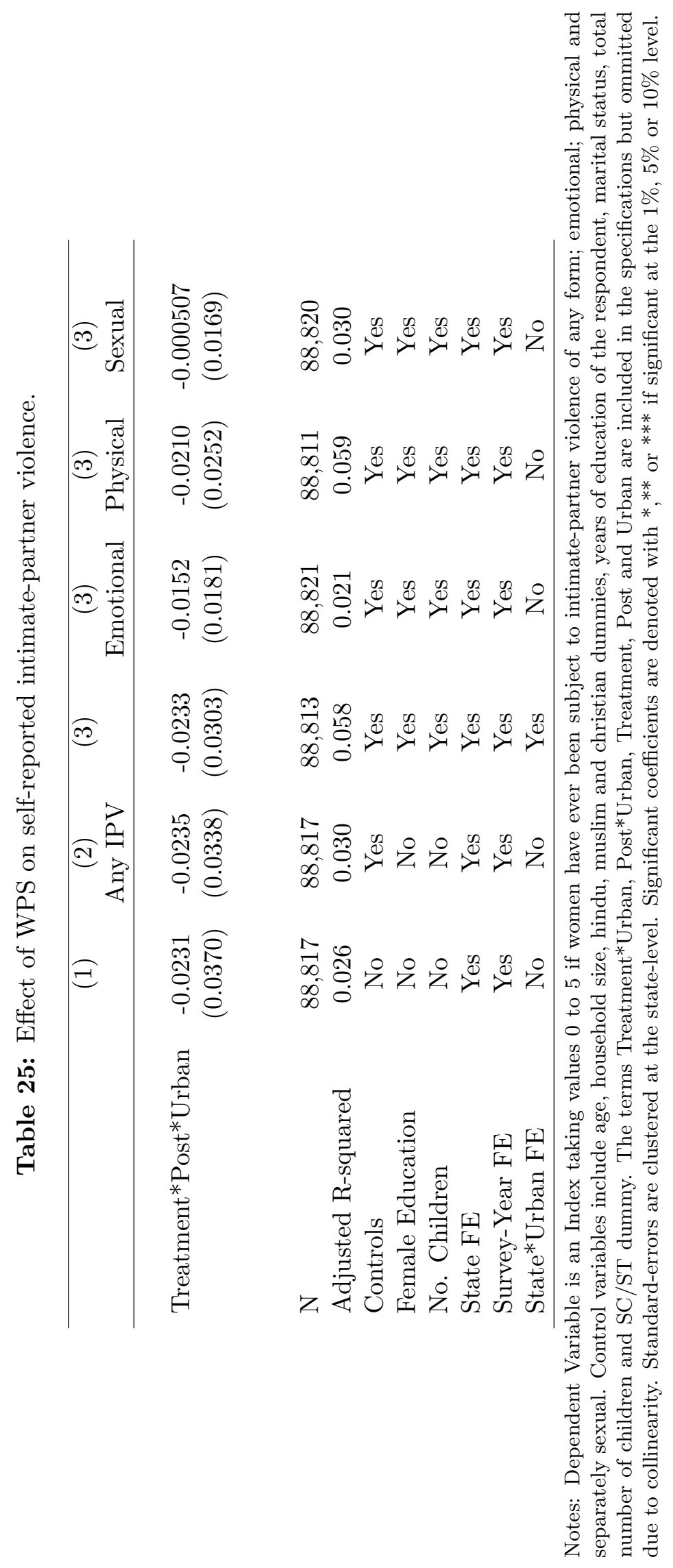


Table 26: State-Level Variation in WPS Policy - DHS Sample Estimations

\begin{tabular}{llll}
\hline States & Pre & Post & N \\
& & & \\
\hline Andhra Pradesh & 0 & 34,179 & 34,179 \\
Assam & 0 & 4,910 & 4,910 \\
Bihar & 3,818 & 1,696 & 5,514 \\
Chattisgarh & 13,012 & 0 & 13,012 \\
Gujarat & 0 & 14,519 & 14,519 \\
Haryana & 2,790 & 746 & 3,536 \\
Himachal Pradesh & 3,193 & 10,428 & 13,621 \\
Jharkhand & 0 & 32,443 & 32,443 \\
Karnataka & 0 & 47,973 & 47,973 \\
Kerala & 0 & 8,370 & 8,370 \\
Madhya Pradesh & 0 & 18,706 & 18,706 \\
Maharashtra & 13,046 & 0 & 13,046 \\
Orissa & 0 & 18,133 & 18,133 \\
Punjab & 3,681 & 14,294 & 17,975 \\
Rajasthan & 0 & 4,688 & 4,688 \\
Tamil Nadu & 0 & 103,580 & 103,580 \\
Uttar Pradesh & 0 & 13,576 & 13,576 \\
Uttarkhand & 48,765 & 0 & 48,765 \\
West Bengal & 6,794 & 62,803 & 69,597 \\
\hline Total & 95,099 & 391,044 & 486,143 \\
\hline
\end{tabular}




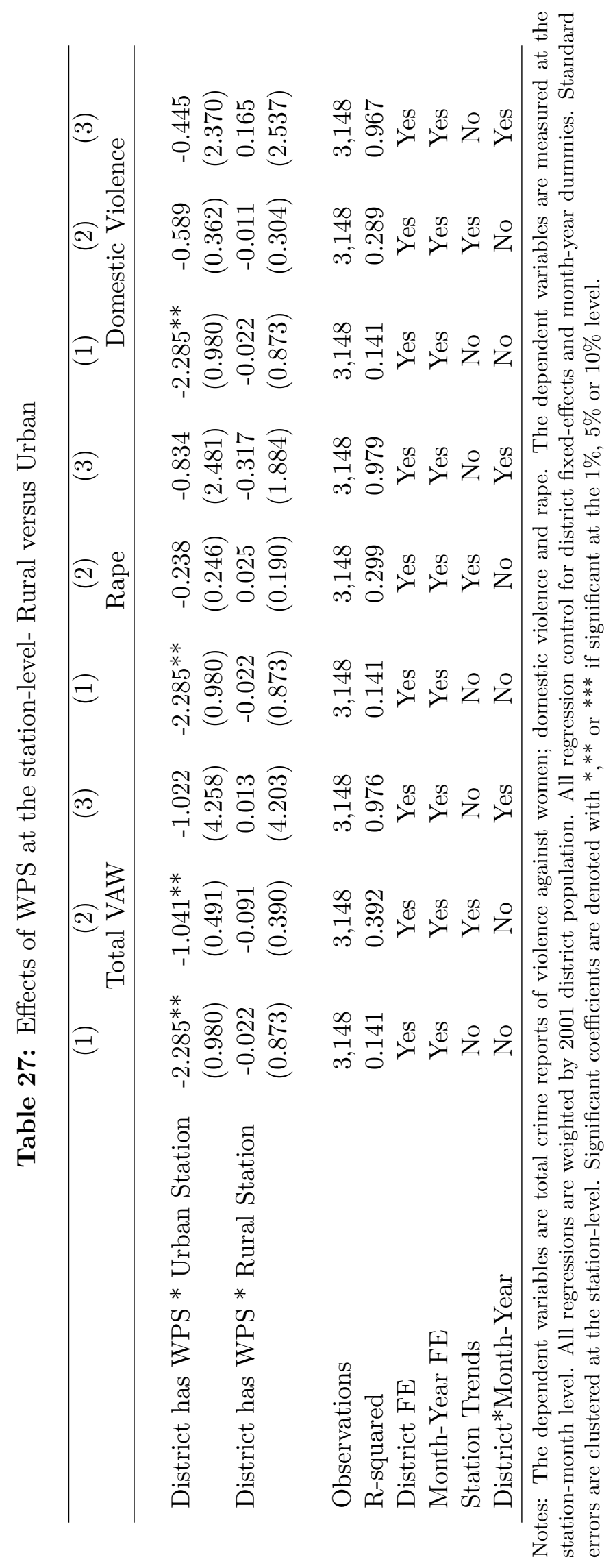

